\title{
1 Developmental and biophysical determinants of grass leaf size worldwide
}

3 Authors: Alec S. Baird ${ }^{1 *}$, Samuel H. Taylor ${ }^{2,3}$, Jessica Pasquet-Kok ${ }^{1}$, Christine Vuong ${ }^{1}, Y u$

4 Zhang $^{1}$, Teera Watcharamongkol ${ }^{3,4}$, Christine Scoffoni ${ }^{1,5}$, Erika J. Edwards ${ }^{6}$, Pascal-Antoine 5 Christin ${ }^{3}$, Colin P. Osborne ${ }^{3}$ Lawren Sack $^{1 *}$

7 Affiliations:

$8{ }^{1}$ Department of Ecology and Evolutionary Biology, University of California Los Angeles, 621

9 Charles E. Young Drive South, Los Angeles, CA 90095, USA.

$10 \quad{ }^{2}$ Lancaster Environment Centre, University of Lancaster, Lancaster LA1 4YW, UK.

$11{ }^{3}$ Department of Animal and Plant Sciences, University of Sheffield, Sheffield S10 2TN, UK.

$12{ }^{4}$ Faculty of Science and Technology, Kanchanaburi Rajabhat University, Muang District, 13 Kanchanaburi, Thailand 7100.

$14{ }^{5}$ Department of Biological Sciences, California State University Los Angeles, 5151 State 15 University Drive, Los Angeles, CA 90032, USA.

$16{ }^{6}$ Department of Ecology and Evolutionary Biology, Yale University, New Haven, CT 06520, 17 USA.

$18 *$ Correspondence to: alecsbaird@gmail.com and lawrensack@ucla.edu 
22 One of the most striking ecological trends is the association of small leaves with dry and

23 cold climates, described 2400 years ago by Theophrastus, and recently recognized for 24 eudicotyledonous plants at the global scale ${ }^{1-3}$. For eudicotyledons, this pattern is attributed

25 to small leaves having a thinner boundary layer to avoid extreme leaf temperatures ${ }^{4}$, and 26 their developing vein traits that improve water transport under cold or dry climates ${ }^{5,6}$. Yet, 27 the global distribution of leaf size and its mechanisms have not been tested in grasses, an 28 extraordinarily diverse lineage, distinct in leaf morphology, which contributes $33 \%$ of 29 terrestrial primary productivity, including the bulk of crop production ${ }^{7}$. Here we 30 demonstrate that grasses have shorter and narrower leaves under colder and drier climates 31 worldwide. We show that small grass leaves have thermal advantages and vein 32 development that contrast with those of eudicotyledons, but that also explain the 33 abundance of small leaves in cold and dry climates. The worldwide distribution of grass

34 leaf size exemplifies how biophysical and developmental processes result in convergence 35 across major lineages in adaptation to climate globally, and highlights the importance of 36 leaf size and venation architecture for grass performance in past, present and future 37 ecosystems. 
38 The grasses (family Poaceae) originated at least $55 \mathrm{Mya}^{8}$ and include $\sim 11,500$ species in 750 39 genera ${ }^{9}$, dominating up to $43 \%$ of the Earth's surface ${ }^{7}$ (Fig. 1). Small leaves have been linked 40 with arid climates in specific grass lineages and communities (Supplementary Table 1). A 41 worldwide climatic association could importantly influence species' distributions, tolerance of 42 climate change, and crop breeding. We tested relationships of leaf size with climate across 1752 43 grass species from 373 genera in a global database and for 27 diverse and globally distributed 44 species in a common garden (Extended Data Fig. 1, Supplementary Table 2 and 3).

45 We also tested for an adaptive basis for the association of grass leaf size with climate 46 (Fig. 1). Because smaller leaves couple more tightly with air temperature due to their thinner 47 boundary layer, small-leafed eudicots avoid damage from night-time chilling and daytime 48 overheating $^{4}$, and they may also achieve higher photosynthetic rate and water use efficiency and 49 compensate for shorter growing periods ${ }^{4,10-12}$. We evaluated these potential advantages for small 50 leafed grasses using energy balance modeling.

Smaller leaves may also develop vein traits that confer stress tolerance ${ }^{5}$. In typical 52 eudicots, the large ("major") veins are patterned before the bulk of leaf expansion 5 , and leaves 53 that expand less have narrower major veins and xylem conduits, and major veins more closely 54 spaced, resulting in a higher major vein length per leaf area (major VLA) ${ }^{5,6}$. Across eudicots, 55 major vein traits scale allometrically with mature leaf size:

$$
\text { Trait }=a \times \text { leaf } \text { area }^{b}
$$

57 where $a$ is a scaling coefficient and $b$ the scaling exponent ${ }^{13}$. These major vein traits in small 58 eudicot leaves can provide greater water transport and lower vulnerability to freezing and 59 dehydration $^{6}$ (Fig. 1a, Supplementary Table 4). Yet grass leaves are highly distinct, with parallel 60 longitudinal veins connected by transverse veins ${ }^{14}$. To determine vein scaling, and its adaptive 61 consequences for small grass leaves, we synthesized a model of $\mathrm{C}_{3}$ and $\mathrm{C}_{4}$ grass leaf 62 development (Box 1, Table 1). For 27 grass species in a common garden, we compared the 63 predicted scaling relationships against null expectations from geometric scaling, ${ }^{5,13}$ (Extended 64 Data Fig. 1, Supplementary Table 3). We tested whether developmental scaling would confer 65 small leaves with potential climatic advantages. 
Box 1. Synthetic model of grass leaf vein development based on published data for 20 species (Supplementary Tables 5-6), conferring small leaves with traits advantageous under cold and dry climates

Grass leaf development includes five phases based on developmental zones:

Phase P (formation and expansion of the primordium, P): "Founder cells" in the periphery of the shoot apical meristem generate the leaf primordium. Cell divisions drive growth of a hood-like structure, in which the central $1^{\circ}$ vein (midvein) and the large $2^{\circ}$ veins are initiated early and extend acropetally, enabling their prolonged diameter growth (Box 1 Fig. 1a, c, e). Henceforth, discrete spatial growth zones develop at the leaf base and drive leaf expansion laterally and longitudinally.

Phase D (formation of the cell division zone, DZ): The basal cell division zone (DZ) expands slightly, driving minimal growth (Box 1 Fig. 1a, b). The $1^{\circ}$ and $2^{\circ}$ vein orders (major veins) complete their patterning basipetally along the leaf blade and increase in diameter (Box 1 Fig. 1c, e). Meanwhile, beginning at the lamina tip, $\mathrm{C}_{3}$ species form a single order of small longitudinal minor veins, i.e., $3^{\circ}$ veins, as do most $\mathrm{C}_{4}$ species, i.e., $\mathrm{C}_{4-3 \mathrm{~L}}$ species. Some $\mathrm{C}_{4}$ species of the subfamily Panicoideae additionally form smaller $4^{\circ}$ veins, i.e., $\mathrm{C}_{4-4 \mathrm{~L}}$ species $^{15}$ (Box 1 Fig. 1c).

Phase D-E (DZ, and formation of the expansion zone, EZ): Cells from the DZ transition to a distinct, distal expansion zone (EZ). In the EZ, cell expansion in width and length spaces apart the $1^{\circ}$ and $2^{\circ}$ veins, resulting in the declines in their vein length per leaf area (Box 1 Fig. 1a, b, d). Additional $3^{\circ}$ veins (and in some species, $4^{\circ}$ veins) continue to initiate at the leaf tip between major vein orders and extend basipetally (Box 1 Fig. 1c-e). The transverse $5^{\circ}$ veins form last, connecting the longitudinal veins.

Phase D-E-M (DZ, EZ and the maturation zone, MZ): Cells from the EZ mature distally, generating the maturation zone (MZ), which increases in size as cells file through the developmental zones (Box 1 Fig. 1a). The venation xylem, phloem and bundle sheath mature.

Phase M (all leaf is MZ): Leaf development is complete with all cells differentiated and expanded (Box 1 Fig. 1a-b).

Given that this developmental model is conserved across grass species, scaling predictions can be derived for species varying in leaf size (Supplementary Table 6). Some of these scaling relationships arise intrinsically from the sequence of development. Thus, major vein length per area (VLA) would be lower in wider leaves, as their major veins are spaced further apart. The $1^{\circ}$ VLA declines geometrically as the inverse of leaf width, whereas the $2^{\circ}$ VLA would decline less steeply than geometrically, as the formation of more $2^{\circ}$ veins would partially counteract their greater spacing. Other scaling trends are not intrinsic, but "enabled" by the developmental $\operatorname{program}^{15}$. The diameters of $1^{\circ}$ and $2^{\circ}$ veins are expected to scale positively with leaf length and area, because a greater leaf length expansion rate or duration enables greater vein diameter growth. Similarly, a positive scaling of $1^{\circ}$ and $2^{\circ}$ vein xylem conduit diameters with vein diameter is enabled by the greater vein expansion in larger leaves.

Minor veins differ from major veins in their predicted scaling with leaf size across species. As minor veins are initiated at the developing leaf tip, greater length expansion provides more space and time for initiating additional minor veins, and thus minor VLA would scale positively with final leaf length. However, as minor veins are initiated later during leaf width expansion, and their diameter growth and spacing is more limited, their vein traits would be independent of final width. The positive scaling of minor VLA with leaf length and its decoupling from leaf width would result in a weak positive scaling of minor VLA with leaf area. Total VLA, i.e., summing major and minor veins, would be decoupled from leaf area, due to the negative scaling of major VLA with leaf width and the positive scaling of minor VLA with leaf length. Additional scaling predictions arise from the scaling of vein diameters and lengths with leaf size (Supplementary Table 6). Like major vein diameters, vein surface and projected areas and volumes per leaf area (VSA, VPA and VVA, respectively) would scale positively with leaf length, and, like major VLA, negatively with leaf width. These counteracting trends lead to predictions that VSA, VPA and VVA are decoupled from leaf area.

The developmental model predicts that grass species with smaller leaf dimensions would develop vein traits conferring stress tolerance, including narrower major veins and higher major VLA, VSA, VPA and VVA, which contribute to water transport efficiency and lower vulnerability to cold and drought ${ }^{5,6}$ (Fig. 1a, Supplementary Table 4). Yet, large grass leaves can attain high minor and total VLA, VSA, VPA and VVA, independently of leaf size, enabling high transport efficiency to compete in sunny, moist climates.

$\mathrm{C}_{3}$ and $\mathrm{C}_{4}$ species were predicted to converge in their vein scaling. $\mathrm{C}_{4}$ grasses have higher total VLA, providing a large vein bundle sheath compartment for concentrating $\mathrm{CO}_{2}$ to enable high rates of photosynthetic assimilation ${ }^{15-17}$. We hypothesized the high total VLA of $\mathrm{C}_{4}$ grasses arises from minor VLA, and therefore independently of leaf area. 


\section{Relationship of leaf size with climate}

69 Globally, grasses vary by more than 625-fold, 275-fold, and 160,000-fold in leaf length, width and area respectively ${ }^{8,18}$ and smaller leaves are associated with cooler and drier climates (Fig. 1b,

71 1c; Supplementary Tables 1-2, 7). Across species, leaf length, width and area were inter-related, 72 and all were positively correlated with mean annual temperature (MAT), mean annual 73 precipitation (MAP), and aridity index (AI) (for leaf area, $r=0.24-0.31, P<0.001$; phylogenetic $74 r=0.08-0.17, P<0.001$; Fig. 1c, Extended Data Fig. 2, Supplementary Table 7). Similar 75 relationships were found with growing season temperature and precipitation (GST and GSP, respectively) and growing season length (Supplementary Table 7). The climatic associations of smaller leaves were independent of plant stature, and statistically similar for $\mathrm{C}_{3}$ and $\mathrm{C}_{4}$ species (Supplementary Tables 7-8). Grass leaf size was associated interactively with MAT and MAP, and with GST and GSP (Extended Data Fig. 3, Supplementary Table 8). The climatic distribution of grass leaf size arises at least in part from exclusion of large-leafed species from dry and cold climates (Extended Data Fig. 4, Supplementary Table 8).

\section{Thermal benefits of small leaf size}

84 We tested three hypotheses for thermal advantages of small leaves for grasses in cold and dry 85 climates using heuristic energy budget modeling ${ }^{19,20}$. First, small leaves may avoid chilling or overheating damage, a mechanism that explains the global biogeographic trend in eudicot leaf size $^{3}$. However, $98 \%$ of grass species in the global database had leaves smaller than modelled width thresholds for such damage, i.e., 8.16 and $4.47 \mathrm{~cm}$, respectively ${ }^{3}$ and among these species leaf size remained associated with climate (Extended Data Fig. 5), indicating that this mechanism cannot explain the global trend. Second, small leaves, being better coupled with air

91 temperature, may achieve higher light-saturated photosynthetic rate (A) or leaf water use

92 efficiency (WUE) under cold or dry climates ${ }^{20}$ (Supplementary Table 9; Extended Data Fig 5).

93 These benefits were supported by model simulations, especially at slower wind speeds;

94 comparing the $5^{\text {th }}$ with the $95^{\text {th }}$ percentile of leaf sizes in our global database, the smaller leaves

95 had 9-27\% higher A and/or WUE under cold or dry climates (Supplementary Table 9). Third,

96 smaller leaves may mitigate the short daily and/or seasonal growth period associated with cold

97 and dry regions with a higher $\mathrm{A}$ under warm and moist conditions ${ }^{4}$, a benefit supported by our 
simulations, which also showed that smaller leaves had higher transpiration rates (Supplementary

99 Table 9).

100

101

\section{Developmental scaling of grass venation}

102 Developmental vein scaling results in strong association of vein traits with grass leaf size. As predicted, globally, smaller leaved species had higher major VLA $(r=-0.84$ to $-0.75, P<0.001$;

104 Fig. 1d, Extended Data Fig. 6). For the 27 grass species grown in the common garden, 105 developmental scaling was supported over the null hypothesis of geometric scaling for numerous vein traits (91 versus 27 of the 111 scaling predictions; $P<0.001$; proportion test; Figs. 2-3, Table 1, Extended Data Figs. 6-7, Supplementary Tables 10-11). The diameters of $1^{\circ}$ and $2^{\circ}$ veins scaled positively with leaf length and area $(b=0.32-0.37 ; r=0.61-0.76 ; P<0.001 ;$ Fig. 2 , Extended Data Fig. 6), and the diameters of xylem conduits scaled with their vein diameters $(b=$ 1.3-1.5; $r=0.48-0.65, P<0.05-0.001$; Extended Data Fig. 6). The $1^{\circ}$ VLA decreased geometrically with increasing leaf width and area $(b=-1.0$ and -0.56 respectively; $r=-1.00$ and $0.61, P<0.001)$, whereas the $2^{\circ}$ VLA decreased less steeply $(b=-0.62$ and $-0.31 ; r=-0.82$ and -

$1130.46, P<0.05$; Fig. 2, Extended Data Fig. 6), and the major and total VLA scaled negatively 114 with leaf width $(b=-0.67$ and $-0.32 ; r=-0.87$ and $-0.56, P<0.01)$. The diameters of minor veins 115 were independent of leaf length, width and area. The predicted trends of $3^{\circ}$ and $4^{\circ}$ VLA with leaf 116 length were not significant, but their sum, the total minor VLA, scaled positively with leaf length $117(b=0.35-0.36 ; r=0.56-0.57, P<0.01)$, and was independent of leaf width and area. The vein 118 surface area, projected area and volume per leaf area (VSA, VPA and VVA respectively) also 119 scaled positively with leaf length, and negatively with leaf width, with the exception of only $3^{\circ}$ 120 VVA, and all were independent of leaf area (Extended Data Fig. 7). Beyond the predictions of 121 the developmental model, the $5^{\circ}$ VLA, VSA and VPA scaled positively with leaf width $(r=$ $0.46-0.57, P<0.05)$.

$123 \quad \mathrm{C}_{3}$ and $\mathrm{C}_{4}$ grasses converged in vein scaling (Fig. 2, Extended Data Fig. 8, Supplementary 124 Table 3). $\mathrm{C}_{4}$ species had more numerous, narrower $3^{\circ}$ veins with higher VLA, VSA and VPA, 125 and 7/16 of the $\mathrm{C}_{4}$ species had $4^{\circ}$ veins, resulting in $\mathrm{C}_{4}$ species having on average almost double 126 the total VLA of the $\mathrm{C}_{3}$ species. The $\mathrm{C}_{4}$ species also had narrower $5^{\circ}$ veins with lower VSA, 127 VPA, and VVA $(P=0.001-0.05)$. 
130 Across the 27 grass species grown experimentally, a number of key vein traits were related to 131 species' native climates. Small leaf size and higher major VLA, VSA, VPA and VVA were 132 associated with lower MAP, AI, GSP, and GSL (Supplementary Table 7). Further, tests 133 supported the assumptions based on the published literature (Supplementary Table 4) that $\mathrm{C}_{3}$ 134 grasses adapted to colder or drier climates have higher light-saturated photosynthetic rates in 135 moist soil, associated with their major vein traits (Extended Data Fig. 9)

136 Developmental scaling would contribute mechanistically to climate adaptation. Globally, 137 vein scaling trends can explain the absence of leaves larger than $51.4 \mathrm{~cm}^{2}$ where MAT $<0{ }^{\circ} \mathrm{C}$ 138 (Extended Data Fig. 5), as their midrib conduits would be wider than $35 \mu \mathrm{m}$ (Extended Data Fig. 139 6), and thereby vulnerable to freeze-thaw embolism ${ }^{21}$. The narrow xylem conduits of small 140 leaves would protect against embolism during drought, and their higher major VLA provides a 141 high capacity flow around blockages, further reducing hydraulic vulnerability to dehydration

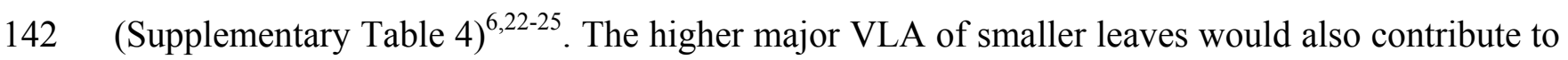
143 mitigating shorter growing periods associated with colder, drier climates ${ }^{11,12}$, by providing higher

144 hydraulic conductance, enabling the maintenance of open stomata for higher photosynthetic rate 145 despite the higher transpiration loads expected from their thinner boundary layer (Extended Data 146 Fig. 9) $)^{6,26}$.

\section{Discussion}

149 The worldwide association of small grass leaf size with cold and arid climates arises from 150 millions of years of grass migration and evolution, from the tropics to colder, drier climates and 151 from forest understoreys to open grasslands ${ }^{8}$ (Supplementary Table 1). The biophysical and 152 developmental advantages of small grass leaves can explain this pattern. The thinner boundary 153 layer of small grass leaves confers moderately higher photosynthetic rate and water use 154 efficiency in cold and dry climates, and can mitigate shorter growing days and seasons, 155 especially under the very low wind speeds expected for closed, dense stands ${ }^{27-30}$. Their higher 156 major VLA and narrower xylem conduits directly contribute to cold and drought tolerance. The 157 strong climatic association of leaf size and vein traits indicates a substantial importance against 158 the background of other adaptations, including leaf hairs, leaf rolling and mesophyll desiccation 
159 tolerance, and beyond leaves, annual vs. perennial life history, stem and root hydraulic 160 adaptation, and root morphology ${ }^{31-33}$.

161 Developmentally-based vein scaling relationships held strongly across diverse grass 162 species, even including those possessing a pseudopetiole, such as bamboos. These relationships 163 may also apply to nongrass species from other families within the Poales. Grass developmental 164 vein scaling relationships were distinct though analogous to those of typical eudicot leaves (Box 165 1, Figs. 1-2). In eudicots, as expected from their diffuse lamina growth, major vein traits scale 166 negatively with final leaf area (Supplementary Table 4), whereas in grasses, vein traits scale 167 more directly with length or width (Box 1, Table 1, Fig. 2). Yet, for both grasses and eudicots, 168 total VLA, a key determinant of hydraulic capacity and photosynthetic rate ${ }^{6}$, was independent of 169 final leaf area. This lack of constraint on total VLA would enable grass diversification in leaf 170 size across environments as for eudicots $5,26,34$, as large-leafed grasses, despite their low major 171 VLA, can achieve sufficient hydraulic capacity with their minor vein length to occupy wet, 172 sunny habitats ${ }^{6}$ 34,35 The decoupling of total VLA from leaf size also enables $\mathrm{C}_{4}$ species to 173 achieve higher VLA than $\mathrm{C}_{3}$ species, irrespective of leaf size (Box 1, Fig. 2). However, unlike 174 eudicots $^{5}$, in grasses, larger leaves did not have higher VVA, a trait that contributes substantially 175 to leaf construction $\operatorname{cost}^{36}$, indicating less restriction on their leaf size evolution in resource-rich 176 environments, where larger leaves may confer advantages in light-use efficiency, and by shading 177 other species ${ }^{37,38}$. While the common developmental program across species explains many vein 178 scaling relationships, these may also arise from selection based on function. In longer leaves, 179 larger diameter veins may provide necessary structural and hydraulic support ${ }^{6,39}$ In wider leaves, 180 more numerous $5^{\circ}$ transverse veins may reinforce against bending ${ }^{40}$, and provide hydraulic 181 pathways mitigating their lower major $\mathrm{VLA}^{6}$. Similarly, the greater $5^{\circ}$ vein diameters in $\mathrm{C}_{3}$ than $182 \mathrm{C}_{4}$ species may compensate for their lower minor VLA (Fig. 2).

183 The relationships of grass leaf size and vein traits to climate have diverse potential 184 applications. In eudicots, these traits are frequently included for estimating species' adaptation to 185 climate $^{6}$, an approach that can be extended to grasses. For grasses, as shown for eudicots ${ }^{5,41}$, vein 186 scaling can enable the reconstruction of leaf size fossilized leaf fragments, improving 187 paleoclimate estimation (Extended Data Fig. 10). Anticipating future climate change, leaf size 188 and vein traits can be key targets for grass crop design, which is central to food and biofuel 189 security $^{42,43}$. A current grand challenge is the engineering of $\mathrm{C}_{4}$ metabolism into $\mathrm{C}_{3}$ crops such as 
190 rice $^{43}$, and a higher total VLA has been targeted as a promising step ${ }^{44,45}$. Global trends indicate 191 that $\mathrm{C}_{4}$ species with narrow leaves and high major VLA would be especially advantaged under 192 the increased temperature and irregular precipitation expected for grasslands ${ }^{25,46,47}$.

\section{References}

1961 Hort, A. Enquiry into plants, vol. I, by Theophrastus. (Harvard University Press, 1948).

1972 Peppe, D. J. et al. Sensitivity of leaf size and shape to climate: global patterns and 198 paleoclimatic applications. New Phytol. 190, 724-739 (2011).

1993 Wright, I. J. et al. Global climatic drivers of leaf size. Science 357, 917-921 (2017).

2004 Gates, D. M. Transpiration and leaf temperature. Ann. Rev. Plant Physio. 19, 211-238 201 (1968).

2025 Sack, L. et al. Developmentally based scaling of leaf venation architecture explains 203 global ecological patterns. Nat. Commun. 3, 1-10 (2012).

2046 Sack, L. \& Scoffoni, C. Leaf venation: structure, function, development, evolution, 205 ecology and applications in the past, present and future. New Phytol. 198, 983-1000 $206 \quad$ (2013).

2077 Beer, C. et al. Terrestrial gross carbon dioxide uptake: Global distribution and covariation 208 with climate. Science 329, 834-838 (2010).

2098 Gallaher, T. J. et al. Leaf shape and size track habitat transitions across forest-grassland 210 boundaries in the grass family (Poaceae). Evolution 73, 927-946 (2019).

2119 Soreng, R. J. et al. A worldwide phylogenetic classification of the Poaceae (Gramineae) 212 II: An update and a comparison of two 2015 classifications. J. Syst. Evol. 55, 259-290 213 (2017).

21410 Schuepp, P. H. Tansley review No. 59 Leaf boundary layers. New Phytol. 125, 477-507 215 (1993).

21611 Orians, G. H. \& Solbrig, O. T. A cost-income model of leaves and roots with special 217 reference to arid and semiarid areas. Am. Nat. 111, 677-690 (1977).

21812 Körner, C. Plant adaptation to cold climates. F1000 Research 5, 1-5 (2016).

21913 Niklas, K. J. Plant Allometry: the scaling of form and process. (University of Chicago $220 \quad$ Press, 1994). 
22114 Nelson, T. \& Dengler, N. Leaf vascular pattern formation. Plant Cell 9, 1121-1135 $222 \quad$ (1997).

22315 Christin, P. A. et al. Anatomical enablers and the evolution of $\mathrm{C}_{4}$ photosynthesis in 224 grasses. P. Natl. Acad. Sci. USA 110, 1381-1386 (2013).

22516 Ueno, O., Kawano, Y., Wakayama, M. \& Takeda, T. Leaf vascular systems in $\mathrm{C}_{3}$ and $\mathrm{C}_{4}$ grasses: A two-dimensional analysis. Ann. Bot-London 97, 611-621 (2006).

22717 Sage, R. F. The evolution of $\mathrm{C}_{4}$ photosynthesis. New Phytol. 161, 341-370 (2004).

22818 Clayton, W. D., Vorontsova, M. S., Harman, K. T. \& Williamson, H. GrassBase - The 229 Online World Grass Flore, $<$ http://www.kew.org/data/grasses-db.html $>$ (2006). Parkhurst, D. F. \& Loucks, O. L. Optimal leaf size in relation to environment. J. Ecol. 60, 505-537 (1972).

Okajima, Y., Taneda, H., Noguchi, K. \& Terashima, I. Optimum leaf size predicted by a novel leaf energy balance model incorporating dependencies of photosynthesis on light and temperature. Ecol. Res. 27, 333-346 (2011). and cavitation caused by freezing. Am. J. Bot. 86, 1367-1372 (1999).

Blackman, C. J., Brodribb, T. J. \& Jordan, G. J. Leaf hydraulic vulnerability is related to conduit dimensions and drought resistance across a diverse range of woody angiosperms. New Phytol. 188, 1113-1123 (2010).

23 Scoffoni, C., Rawls, M., McKown, A., Cochard, H. \& Sack, L. Decline of leaf hydraulic conductance with dehydration: Relationship to leaf size and venation architecture. Plant Physiol. 156, 832-843 (2011).

24525 Craine, J. M. et al. Global diversity of drought tolerance and grassland climate-change 246 resilience. Nat. Clim. Change 3, 63-67 (2013).

24726 Scoffoni, C. et al. Hydraulic basis for the evolution of photosynthetic productivity. Nat. $248 \quad$ Plants 2, 1-8 (2016).

24927 Jones, H. G. Plants and microclimate : a quantitative approach to environmental Plant $250 \quad$ Physiol.. Third edition. edn, (Cambridge University Press, 2014).

25128 Grace, J. Plant-atmosphere relationships. 1st edn, (Chapman and Hall Ltd, 1983). 
25229 Weiser, R. L., Asrar, G., Miller, G. P. \& Kanemasu, E. T. Assessing grassland biophysical characteristics from spectral measurements. Remote Sens. Environ. 20, 141152 (1986).

30 Meinzer, F. C. G., D. A. Stomatal control of transpiration from a developing sugarcane canopy. Plant Cell Environ. 12, 635-642 (1989).

31 Liu, H. et al. Life history is a key factor explaining functional trait diversity among subtropical grasses, and its influence differs between $\mathrm{C}_{3}$ and $\mathrm{C}_{4}$ species. J. Exp. Bot. 70, 1567-1580 (2019).

32 Fort, F., Jouany, C. \& Cruz, P. Root and leaf functional trait relations in Poaceae species:

33 Holloway-Phillips, M. M. \& Brodribb, T. J. Contrasting hydraulic regulation in closely related forage grasses: implications for plant water use. Funct. Plant Biol. 38, 594-605 (2011).

Brodribb, T. J., Feild, T. S. \& Sack, L. Viewing leaf structure and evolution from a hydraulic perspective. Funct. Plant Biol. 37, 488-498 (2010).

40 Niklas, K. J. A mechanical perspective on foliage leaf form and function. New Phytol. 143, 19-31 (1999).

28041 Merkhofer, L. et al. Resolving Australian analogs for an Eocene Patagonian paleorainforest using leaf size and floristics. Am. J. Bot. 102, 1160-1173 (2015).

42 Somerville, C. The billion-ton biofuels vision. Science 312, 1277-1277 (2006). 
43 Sedelnikova, O. V., Hughes, T. E. \& Langdale, J. A. Understanding the genetic basis of $\mathrm{C}_{4}$ kranz anatomy with a view to engineering $\mathrm{C}_{3}$ crops. Ann. Rev. Gen. 52, 249-270

44 Sage, R. F. \& Zhu, X. G. Exploiting the engine of $\mathrm{C}_{4}$ photosynthesis. J. Exp. Bot. 62, 2989-3000 (2011).

46 Edwards, E. J. et al. The origins of $\mathrm{C}_{4}$ grasslands: Integrating evolutionary and ecosystem

47 Linder, H. P., Lehmann, C. E. R., Archibald, S., Osborne, C. P. \& Richardson, D. M. science. Science 328, 587-591 (2010).

Global grass (Poaceae) success underpinned by traits facilitating colonization, persistence and habitat transformation. Biol. Rev. 93, 1125-1144 (2018).

\section{Main Figure/Display Legends}

312 represent the $2 \mathrm{~d}$ kernel density of points. (d) The association of major vein length per area

313 (VLA $\left.A_{\text {major }}\right)$ with leaf area across grass species $(n=600$ species). Statistics represent the fits for 
$314 \log (\mathrm{y})=\log (a)+b \log (\mathrm{x})$ from ordinary least squares in (c) and (d). $P=$ (c) $2.3 \times 10^{-27}$ and (d) $3151.6 \times 10^{-139}$ (both two-tailed).

Fig. 2. The scaling of vein traits with leaf dimensions for 27 species of $C_{3}$ and $C_{4}$ grasses 318 grown in a common garden. (a) - (d) Relationships of vein diameters with leaf length and (e) -

319 (h) of vein lengths per unit leaf area with leaf width: (a) \& (e) first order $\left(1^{\circ}\right)$ veins (b) \& (f) 320 second order $\left(2^{\circ}\right)$ veins (c) \& (g) third order $\left(3^{\circ}\right)$ veins, and, for the species that possess them, 321 fourth order $\left(4^{\circ}\right)$ veins (inset panels) and (d) \& (h) fifth order $\left(5^{\circ}\right)$ transverse veins. Each point 322 represents a species mean value $\left(n=11 C_{3}\right.$ in white and $n=16 C_{4}$ in gray). Reduced major axis 323 (PRMA) or phylogenetic generalized least square regressions were fitted for log (vein diameter 324 or vein length per area) $=\log (a)+b \log$ (leaf length or width), respectively; parameters and 325 goodness of fit in Table 1 and Supplementary Table 10. ${ }^{* *} P<0.01,{ }^{* * *} P<0.001 ; P=$ (a) 3260.0007 , (b) $3.9 \times 10^{-6}$, (e) $1.2 \times 10^{-34}$, (f) $1.4 \times 10^{-7}$ and (h) 0.0020 (all two-tailed). Significant 327 trends are plotted with PRMA. Standard errors for species trait values are found in 328 Supplementary Table 3.

Box 1 Fig. 1 Synthetic model for grass leaf ontogeny predicting developmentally-based scaling of vein traits with final leaf size across species. Processes are plotted against developmental phases: phases $\mathrm{P}$ and $\mathrm{D}$, formation of the leaf primordium and the cell division zone at the base of the leaf (DZ), respectively; phases D-E and D-E-M, the additions of the 334 expansion zone (EZ) and the maturation zone, resepctively; and phase M, maturation of the whole leaf blade. (a) Leaf expansion and the formation of zones; (b) Increases of leaf length, width and area; (c) Patterning of leaf vein orders from $1^{\circ}$ veins to $5^{\circ}$ transverse veins for $\mathrm{C}_{3}$ and $\mathrm{C}_{4}$ species; some $\mathrm{C}_{4}$ species develop $4^{\circ}$ longitudinal veins $\left(\mathrm{C}_{4-4 \mathrm{~L}}\right.$ species), whereas $\mathrm{C}_{3}$ species and $\mathrm{C}_{4-3 \mathrm{~L}}$ species do not; (d) Increases in vein length per leaf area and (e) in vein diameter for each vein order.

Table 1. Parameters for the scaling of vein diameters and vein lengths per area with

342 mature leaf dimensions across $27 \mathrm{C}_{3}$ and $\mathrm{C}_{4}$ grass species grown in a common garden $(N=$

34311 and 16 respectively). Tolerance of cold or dry climates can be conferred by these vein traits

344 and others (vein surface area per leaf area, projected area per leaf area and volume per leaf area, 
345 shown in Supplementary Table 10), as they influence hydraulic capacity and safety, and vascular

346 cost (Supplementary Table 4). Expectations for these across-species scaling relationships were

347 derived from a developmental model, which predicts the allometric slope $b$ in the equation log

348 (trait) $=\log (a)+b \log$ (mature leaf length, width or area) (Supplementary Table 6), due to

349 intrinsic (i) and enabling (e) effects (Box 1); expectations from the alternative, geometric scaling

350 model were also derived (Supplementary Tables 6 and 10). Allometric equations were fitted

351 using two-tailed phylogenetic reduced major axis (PRMA) or phylogenetic generalized least

352 squares (PGLS) for the scaling of vein diameter or vein length per area, respectively, with $r$ -

353 values and $p$-values, and parameters $a$ and $b$, including 95\% confidence intervals (CIs) for $b$ -

354 values. Bold type indicates that the $b$-values predicted from the developmental model were

355 supported in the experimental, i.e., the scaling relationship across species was significant, and the

356 predicted $b$-value was within the $95 \%$ CIs for the observed $b$-value. Significance: $* P<0.05,{ }^{* *} P$

$357<0.01, * * * P<0.001$, NS: Not significant. 


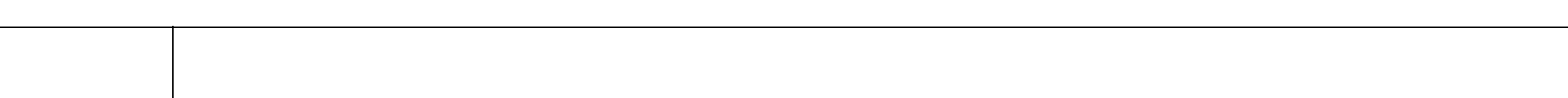


364 Testing for the linkage of leaf size and vein traits with climate across grass species 365 worldwide

366 We extracted data from the Kew Royal Botanic Garden Grassbase, which was compiled from a 367 combination of floristic accounts and publications ${ }^{18}$. We extracted all available data for maximum leaf length, maximum leaf width, maximum $2^{\circ}$ vein number, and maximum culm

369 height data, which included values for up to 1752 species depending on the trait (i.e., up to 912 $370 \mathrm{C}_{3}$ and $840 \mathrm{C}_{4}$ species from 373 genera $)^{18}$. We calculated leaf area by multiplying maximum leaf 371 length by maximum leaf width. We divided the maximum leaf length and maximum $2^{\circ}$ vein 372 number respectively by maximum leaf width to determine $1^{\circ}$ and $2^{\circ}$ vein lengths per area, and 373 summed these to calculate major vein length per area, resulting in values for 616 species for 374 these traits. To test associations of leaf morphological and venation traits with species' native 375 climates, we extracted geographical records from the Global Biodiversity Information Facility 376 web portal (http://www.gbif.org). Species names were checked against the Kew grass synonymy 377 database ${ }^{18}$ via the software package Taxonome ${ }^{48}$ and The Plant List (http://www.theplantlist.org) 378 via package Taxostand in $\mathrm{R}^{49}$. We discarded records if these were duplicates, or names were not 379 recognized in any databases, or the country did not match the coordinates, or coordinates 380 contained fewer than three decimals, or species had fewer than five occurrences. For each 381 location, values for mean annual temperature (MAT), mean annual precipitation (MAP), and 382 mean monthly temperature and precipitation were extracted from WorldClim2 5-arc minute 383 resolution $^{50}$, and for aridity index (AI) ${ }^{51}$ from CRU TS4.01 $01^{52}$. We also estimated growing 384 season variables, considering growing season months as those with mean temperature $\geq 4{ }^{\circ} \mathrm{C}$ and 385 precipitation $\geq 2 \times$ mean monthly temperature; growing season length (GSL) was calculated as 386 the number of those months, growing season temperature (GST) by averaging their mean 387 temperatures, and growing season precipitation (GSP) by summing their mean precipitation ${ }^{53}$. 388 Climate variables were averaged from all given locations for each species. We focused on the 389 relationships of traits with mean climate variables based on the hypothesis that if gene flow 390 occurs among populations of a given species across its native range, that species' mean 391 phenotypic trait values would be related to their mean climate variables ${ }^{54}$. 
Construction of a synthetic model for grass leaf development, and derivation of allometric 394 predictions based on developmental and geometric scaling

395 To determine whether leaf development would constrain specific vein traits in smaller leaves, we 396 formulated a synthetic grass leaf developmental model and derived expectations for the 397 relationship of vein traits with final leaf dimensions across species (Box 1, Supplementary 398 Tables 5-6). To construct this model, we conducted searches for previously published studies 399 that included developmental data and/or images of grass leaf development using the keywords 400 "grass leaf development, "grass vein development", "grass histogenesis", "grass 401 morphogenesis", "Poaceae", "leaf ontogeny", "leaf histology, "leaf growth, "leaf anatomy", 402 "vascular development", "vasculature development" in the Web of Science database and the 403 Google Scholar search engine, resulting in a compilation of 61 studies of 20 grass species ${ }^{14,55-114}$. 404 From these studies we extracted key steps in leaf and vein development that were general across 405 species into a synthetic model. Then, given the spatial and temporal constraints arising from 406 development according to this model, we derived expectations for the scaling across species of 407 vein traits with mature leaf size. For instance, the $1^{\circ}$ vein length per area declines geometrically 408 with final leaf width $\left(1^{\circ} \mathrm{VLA}=1 /\right.$ leaf width $)$ as veins are separated by greater numbers of cell 409 divisions and/or by larger cells. By contrast, the $2^{\circ}$ VLA declines less steeply than geometrically 410 with final leaf width, as wider leaves may form greater numbers of $2^{\circ}$ veins though these will be 411 spaced further apart by subsequent leaf expansion (see Box 1 and Supplementary Table 6 for 412 additional derivations).

413 Further, as a null hypothesis against which to test developmentally-based scaling 414 predictions, we derived expectations for the relationships of vein traits to leaf dimensions based 415 on geometric scaling ${ }^{5,13}$. Geometric scaling represents the relationships expected among the 416 dimensions of an object given increases in size while maintaining constant proportions and 417 composition. Thus, linear dimensions such as length $(L)$, area $(A)$ and volume $(V)$ would be inter418 related as $A \propto L^{2}$ and $V \propto L^{3}$. Predictions can then be derived for any other traits based on their 419 dimensions. For instance, given geometric scaling, VLA would be expected to scale with leaf 420 width as VLA $\propto \mathrm{LW}^{-1}$, because VLA, as a linear dimension divided by an area, i.e., $L / A$, would 421 be related to $L / L^{2},=L^{-1}$, whereas $L W$ would scale directly with $L$. In total, 111 predictions 422 derived from the developmental model were compared with respective predictions from 423 geometric scaling. These 111 predictions included the scaling relationships of five vein 
424 diameters (i.e., for each of five vein orders) versus three leaf dimensions (i.e., leaf length, width 425 and area), amounting to 15 predictions; plus the scaling relationships for VLA, VSA, VPA and 426 VVA for each of the five vein orders and for the major, vein, and total vein systems, versus the 427 three leaf dimensions, amounting to $4 \times 8 \times 3=96$ predictions. The developmental model 428 predictions for relationships generally differed strongly from those of geometric scaling (i.e., $42975 \%$ of predictions differed), though, for a few relationships, such as that of $1^{\circ}$ VLA with final 430 leaf size, the expectations from developmental scaling and geometric scaling were the same. 431 Overall, developmental scaling predicted that 51 vein traits would scale with leaf size and 60 432 traits would be independent of leaf dimensions, whereas geometric scaling predicted 63 and 48 433 respectively (Supplementary Table 6 and 10).

\section{$435 \quad$ Plant material}

436 To test vein scaling relationships, grasses of 27 diverse species were grown in a common garden 437 to reduce the environmentally-induced plasticity that would occur in wild plants in their native 438 ranges (Extended Data Fig. 2, Supplementary Table 3). While experimental species were 439 selected to encompass large phylogenetic and functional variation, including $11 \mathrm{C}_{3}$ species and $44016 \mathrm{C}_{4}$ species, representing 11 independent $\mathrm{C}_{4}$ origins, the species necessarily included a only 441 subset of the phylogenetic distribution of the 1752 species in the database analyses of global 442 trait-climate relationships. Seeds were acquired from seed banks and commercial sources 443 (Supplementary Table 3). Prior to germination, seeds were surface-sterilized with $10 \% \mathrm{NaClO}$ 444 and $0.1 \%$ Triton X-100 detergent, rinsed three times with sterile water, and finally sown on 445 plates of $0.8 \%$ agar sealed with Micropore surgical tape (3M, St. Paul, MN). Seeds were 446 germinated in chambers maintained at $26^{\circ} \mathrm{C}$, under moderate intensity cool white fluorescent 447 lighting with a 12 hour photoperiod. When roots were 2-3 cm long, seedlings were transplanted 448 to $3.6 \mathrm{~L}$ pots with potting soil (1:1:1.5:1.5:3 of coarse vermiculite: perlite: washed plaster sand: 449 sandy loam: peat moss).

450 Plants were grown at the UCLA Plant Growth Center (minimum, mean and maximum 451 daily values for temperature: $20.1,23.4$ and $34.0{ }^{\circ} \mathrm{C}$; for relative humidity: 28 , 50 and $65 \%$; and 452 mean and maximum photosynthetically active radiation during daylight period: 107 and 1988 $453 \mu \mathrm{mol}$ photons $\mathrm{m}^{-2} \mathrm{~s}^{-1}$; HOBO Micro Station with Smart Sensors; Onset, Bourne, MA), arranged 454 in six randomized blocks spread over three benches, with one individual per species per block 
455 and two blocks per bench ( $n=6$ except $n=4$ for Alloteropsis semialata). Plants were irrigated 456 daily with water containing fertilizer (200-250 ppm of 20:20:20 N:P:K; Scotts Peters 457 Professional water soluble fertilizer; Everris International B.V., Geldermalsen, The Netherlands). 458 All species were grown until flowering to confirm species' identities.

\section{Sample anatomical preparation}

461 Leaves were collected when plants had numerous mature leaves, after $2.5-7$ months of growth, 462 depending on species, given variation in growth rates. Leaves from each of six individuals per 463 species were fixed and stored in FAA solution (37\% formaldehyde-glacial acidic acid-95\% 464 ethanol in deionized water). Transverse sections were made for one leaf from each of three 465 individuals. Rectangular samples were cut from the center of leaves halfway along the length of 466 the blade and gradually infiltrated under vacuum with low viscosity acrylic resin for one week 467 (L.R. White; London Resin Co., UK), and set in resin in gelatin capsules to dry at $55{ }^{\circ} \mathrm{C}$ 468 overnight. Transverse cross sections $1 \mu \mathrm{m}$ in thickness were prepared using glass knives (LKB 4697800 KnifeMaker;LKB Produkter; Bromma, Sweden) in a rotary microtome (Leica Ultracut E, 470 Reichert-Jung California, USA), placed on slides, and stained with $0.01 \%$ toluidine blue in $1 \%$ 471 sodium borate $(\mathrm{w} / \mathrm{v})$. Slides were imaged with a light microscope using a $5 \times, 20 \times$, and $40 \times$ 472 objective (Leica Lietz DMRB; Leica Microsystems) and camera with imaging software (SPOT 473 Imaging Solution; Diagnostic Instruments, Sterling Heights, Michigan USA). Additionally, one leaf from each of three individuals was used to prepare chemically cleared leaf sections to 475 visualize veins. Square sections of $1 \mathrm{~cm} \times 1 \mathrm{~cm}$ were cut from the center of the leaf at the widest 476 point, cleared with $5 \% \mathrm{NaOH}$ in ethanol, stained with safranin, and counterstained with fast477 green ${ }^{115}$. Sections were mounted with water in transparency film (CG5000; 3M Visual Systems 478 Division) and scanned (flatbed scanner; Canon Scan Lide 90; 1,200 pixels per inch), and further 479 imaged with a light microscope using a $5 \times$ and $10 \times$ objective.

\section{Quantification of leaf dimensions and vein traits}

482 Leaf dimensions tested were leaf width, leaf length, and leaf area, with leaf width and leaf length 483 measured at the widest and longest regions of the leaf respectively. Leaf area was calculated as 484 leaf length $\times$ leaf width ${ }^{116-118}$. Estimates of leaf area from length and width can be improved by 485 multiplying by a correction factor constant, which has been proposed as 0.7-0.9 for grasses ${ }^{116-118}$, 
486 but as there is no standard value, we did not apply such a correction factor. Applying a constant 487 correction factor would have no influence on correlations or regression fits or their statistical 488 significance for trait-climate relationships. Further, applying a constant correction factor would 489 not influence the tests of scaling of vein traits with leaf area, which focused on power law scaling 490 exponents; multiplying estimates of leaf area by a constant would result only in change to the 491 power law scaling intercept, and not the exponent. Thus, applying a correction factor to leaf area, 492 or not, would have no influence any of the findings of our study.

493 We measured and analyzed cross sections of one leaf for each of three individuals per 494 species, to quantify the diameters and numbers of veins in the transverse plane for all vein 495 orders, excluding $5^{\circ}$ veins, which generally were not visible in transverse sections, and for which 496 we used the chemically cleared and stained leaf sections. Vein orders were established for each 497 species based on vein size, presence/absence of enlarged metaxylem, and presence/absence of 498 fibrous tissue above or below the vein ${ }^{119,120}$. The $1^{\circ}$ vein or midvein was the large central vein 499 containing the largest metaxylem and fibrous tissue, and the $2^{\circ}$ veins were the "large" veins that 500 were substantially smaller than the midvein and of similar structure. We identified the minor 501 veins as the smaller veins, i.e., the $3^{\circ}$ "intermediate" and $4^{\circ}$ "small" veins, and perpendicular $5^{\circ}$ 502 transverse veins ${ }^{120}$. Notably, $4^{\circ}$ veins occur only in NADP-ME $\mathrm{C}_{4}$ grasses of the subfamily 503 Panicoideae $\left(7 / 16 \text { of the } \mathrm{C}_{4} \text { species }\right)^{15}$, and can be distinguished based on their smaller overall 504 size than $3^{\circ}$ veins and their absence of sclerenchyma strands. For the species Lasiacis 505 sorghoidea, $2^{\circ}$ veins were too few to be counted in our prepared transverse sections, and we 506 established vein orders and quantified associated traits using the chemically cleared and stained 507 leaves.

508 For each vein order, the vein length per area (VLA) was quantified as the vein number 509 per leaf width $\left(\mathrm{cm}^{-1}\right.$ or $\left.\mathrm{mm}^{-1}\right)$, which is equivalent to vein length per unit leaf area (same units), 510 assuming an approximately rectangular leaf. Cross-sectional vein diameters (VD) were measured 511 excluding the bundle and mestome sheath cell layers, and averaging horizontal and vertical axes. 512 Cross-sectional diameters were measured for all xylem conduits in each vein order by 513 considering the lumen cross-sections as ellipses and averaging the major and minor axes. We 514 categorized two metaxylem types within major veins, based on their highly distinct sizes (i.e., 515 large and small metaxylem), and one metaxylem type for minor veins (i.e., "small metaxylem"). 516 We focused on the large metaxylem conduits within major veins in calculating average conduit 
517 diameter values, as these would contribute the bulk of maximum flow ${ }^{121,122}$. For Lasiacis

518 sorghoidea, as $2^{\circ}$ veins were too few to be counted from our prepared transverse sections, we 519 could not quantify the conduits within these veins and thus analyses of $2^{\circ}$ vein conduit 520 dimensions excluded this species.

$521 \quad$ For all vein orders, we estimated vein surface per unit leaf area (VSA), vein projected 522 area per unit leaf area (VPA), and vein volume per unit leaf area $\left(\mathrm{VVA}^{55}\right.$

$523 \quad \mathrm{VSA}=\mathrm{VLA} \times \pi \times \mathrm{VD}$

$524 \quad \mathrm{VPA}=\mathrm{VLA} \times \mathrm{VD}$

$525 \quad \mathrm{VVA}=\mathrm{VLA} \times \pi \times(\mathrm{VD} / 2)^{2}$

Determination of vein allometries, and testing against predictions from developmental and 528 geometric scaling

529 We determined trait scaling relationships by fitting lines to log-transformed data. The 530 relationship of each vein trait (y) to a given leaf dimension (x) was considered as an allometric 531 power law:

$532 \mathrm{y}=a \mathrm{x}^{b}$

$533 \log (\mathrm{y})=\log (a)+b \log (\mathrm{x})$

534 where $b$ is the scaling exponent.

535 We tested these relationships against the predictions from developmentally-based scaling 536 derived from the synthetic leaf developmental model (see "Construction of a synthetic model for

537 grass leaf development, and derivation of allometric predictions based on developmental and 538 geometric scaling” and Box 1, Table 1, and Supplementary Table 6) $)^{5}$. A scaling relationship was 539 considered to be consistent with a prediction if its $95 \%$ confidence intervals included the 540 predicted slope. We tested whether a greater proportion of predictions were explained by 541 developmental scaling than by geometric scaling using a proportion test (Minitab 16; State 542 College, Pennsylvania, USA).

\section{Testing assumptions for the linkages of photosynthetic rate with climate and vein traits}

545 For the grass species grown experimentally, light-saturated rates of photosynthesis were 546 measured for plants in moist soil, enabling a test of the assumptions that $\mathrm{C}_{3}$ grass species from 547 arid or cold environments have high photosynthetic rates, and that photosynthetic rate would be 
related to vein length and surface area per leaf area. Light-saturated rates of photosynthesis were measured from $17 \mathrm{Feb}$ to 28 June 2010, between 0900 and 1500, on a mature leaf on each plant for six plants per species. Measurements were taken of steady state gas exchange $(<2 \%$ change over six minutes) using a LI-6400 XT portable photosynthesis system (LI-COR, Lincoln, 552 Nebraska, USA). Conditions within the leaf chamber were set to $25^{\circ} \mathrm{C}$, with reference $\mathrm{CO}_{2} 400$ ppm, and PPFD $2000 \mu \mathrm{mol} \mathrm{m} \mathrm{m}^{-2} \mathrm{~s}^{-1}$, and the relative humidity was $60-80 \%$, resulting in vapor pressure deficits (VPD) of 0.80-1.6 kPa. Measurements were made on 1-2 leaves from each of 6 plants (except L. sorghoidea, 3 leaves from each of two plants). 5-9 leaves per species were measured, with 6 on average. Leaves were harvested and scanned for leaf area (Canon Scan Lide 90, Canon USA, Lake Success, NY). Leaf-area normalized values were determined for net lightsaturated photosynthetic rate per leaf area $\left(A_{\text {area }}\right)$.

In addition, we tested for even stronger general support of the relationships of photosynthetic rate with climate variables by combining our data for $8 \mathrm{C}_{3}$ terrestrial species with data for 13 Northern Hemisphere temperate terrestrial $\mathrm{C}_{3}$ grass species from the GLObal Plant trait NETwork (GLOPNET) database ${ }^{123}$, for which photosynthesis, latitude and longitude data for their field site were available (Supplementary Table 12). We extracted climate variables mean annual temperature (MAT), mean annual precipitation (MAP), and monthly temperature and precipitation to calculate growing season length (GSL) (see Testing for the linkage of leaf size and vein traits with climate across grass species worldwide above for methods of calculation), based on the latitude and longitude from which each species was measured.

\section{Phylogenetic reconstruction}

570 A phylogenetic hypothesis for the 27 experimentally grown species considered in this study was 571 inferred from three markers from the chloroplast genome ( $r b c L, n d h F$ and trnKmatK), available 572 for the exact same accessions in published datasets ${ }^{124,125}$. Each marker was aligned individually 573 using MUSCLE ${ }^{126}$, and the alignments were manually refined. The total dataset was 6179 bp 574 long. The program BEAST ${ }^{127}$ was used to obtain a time-calibrated phylogeny under a relaxed 575 clock model with uncorrelated evolutionary rates that follow a log-normal distribution. The 576 substitution model was set to a general time reversible model with a gamma-shape parameter and 577 a proportion of invariants. The root of the tree (split of BOP and PACMAD clades) was forced to 578 follow a normal distribution with a mean of 51.2 Ma and a standard deviation of $0.0001 \mathrm{Ma}$, 
579 based on previous estimates ${ }^{128}$. The addition of phytolith fossils would alter the absolute ages 580 estimated by molecular dating ${ }^{129}$, but the relative ages would remain unchanged and the comparative analyses consequently would be unaffected. Two parallel analyses were run for $10,000,000$ generations, sampling a tree every 1,000 generations. Median ages across the 18,000

583 trees samples are a burn-in period of 1,000,000 generations were mapped on the maximum credibility tree. The burn-in period was largely sufficient for the analysis to reach stability, as verified with the program Tracer (http://beadt.bio.ed.ac.uk/Tracer).

Using the R Language and Environment version $3.4 .1^{130}$ with the ape R package ${ }^{131}$ a phylogenetic hypothesis for 1752 of the Grassbase species was extracted from a published phylogeny available through Dryad ${ }^{132}$. The source phylogeny assessed relationships among 3595 species using a set of 14 sub trees using various genetic datasets in combination with three core plastid markers $r b c L, n d h F$ and matK, with dating based on macrofossil evidence 9

\section{Testing trait-climate associations}

593 To test trait-climate associations, we quantified the strength of correlations using Pearson $r$ rather 594 than fitting specific predictive regression equations with $R^{2}$ values. For trait-climate associations 595 we calculated both ahistorical correlations and relationships accounting for phylogenetic relatedness (PGLS or PRMA, see section Comparative analyses below). While the phylogenetic analyses more robustly test our evolutionary hypotheses, the ahistorical Pearson $r$ values better resolve the strengths of existing relationships across species, especially when trends arise from 599 variation among groups that split in evolution deep in the phylogeny ${ }^{133}$. In both types of analysis, 600 the $r$ values provide a conservative estimate of trait-climate relationships. As in previous 601 biogeographic trait-climate analyses ${ }^{134,135}$, we related species' average trait values from a 602 database or experimental measurements to modelled native climates based on natural 603 occurrences; relationships would be yet stronger if traits and climate were matched for individual 604 plants ${ }^{136}$. Additionally, the modelled native climates do not account for variation to which 605 species would be adapted in the field in temperature, irradiance and water availability due to 606 microclimate associated with topography and canopy cover, or soil characteristics; accounting 607 for this variation would likely improve the strength of trait-climate relationships ${ }^{136}$. Overall, 608 global associations of traits with climate that were supported by substantial, statistically 609 significant ahistorical $r$ values indicate robust, biologically significant relationships, and 
610 significant phylogenetic correlations additionally indicate support for the evolutionary 611 hypotheses ${ }^{137,138}$.

612 We implemented several further analyses to resolve the associations of traits with climate

613 in the worldwide grass trait database. We conducted phylogenetic multiple regression to test for 614 significant interactive effects of temperature and precipitation on leaf traits. Models including 615 MAT and MAP (or GST and GSP) alone or in combination, and including an interaction were 616 compared using Akaike Information Criterion (AIC) ${ }^{139}$. Prior to phylogenetic multiple regression 617 analyses, MAP values were divided by 50 to achieve a similar scale of values as MAT, and GSP 618 values were divided by 100 to achieve a similar scale of values as GST. Plant traits, MAP and 619 MAT were then log transformed, and MAT and MAP (and GST and GSP) were centered by 620 subtracting the mean to render coefficients of main effects and interaction terms biologically 621 interpretable ${ }^{140}$.

622 The parametric correlation and regression statistics calculated in this study are subject to 623 assumptions, i.e., independence of observations, and the normal distribution and 624 homoscedasticity of residuals ${ }^{141}$. Evolutionary non-independence among species was adjusted 625 for using phylogenetic statistics ${ }^{133}$. To check that the assumptions of normality and 626 heteroscedasticity did not influence statistical significance of univariate analyses, we checked for 627 significance of Spearman's rank correlations, which are not subject to these assumptions, and 628 confirmed as significant $(p<0.05)$ the relationships presented in the text. For the multiple 629 regression of leaf area versus MAT and MAP in the 1752 species global database, the 29 species 630 with MAT $<0{ }^{\circ} \mathrm{C}$ resulted in a left-skew of log-transformed MAT and a notable 631 heteroscedasticity of residuals (Supplementary Fig. 1). To confirm that this skew did not 632 influence the findings of the multiple regressions, we repeated the analysis excluding the 29 633 species, which alleviated the skew and heteroscedasticity (Supplementary Fig. 2); the key finding 634 of the multiple regression analysis, i.e., the interactive effect of MAT and MAP, was unaffected 635 (Supplementary Table 8). Notably, the multiple regression analysis of leaf area versus growing 636 season temperature and growing season precipitation also confirmed the trend, with greater 637 normality and homoscedasticity of residuals, both when including all 1752 species and when 638 excluding the 29 species with MAT $<0{ }^{\circ} \mathrm{C}$ (Supplementary Tables 7 and 8; Supplementary Figs. $6393-4)$. 
We conducted hierarchical partitioning analyses on log transformed data to resolve the 641 independent statistical associations of leaf size with individual climate variables ${ }^{142}$. Finally, we

642 distinguished whether trait-climate correlations can be partially explained due to "triangular 643 relationships", i.e., when data are missing in one or more corners of the plot, an analysis that can 644 provide special insights ${ }^{143,144}$. For example, a positive trait-climate correlation would arise at 645 least in part from a triangular relationship if high trait values are few or absent at lower values of 646 the climate variable, or if low trait values are few or absent at high values of the climate variable.

647 To test for the presence of triangular relationships, we implemented quantile regression analyses, 648 determining regression slopes fitted through the 5\%,50\% and 95\% quantiles of log transformed 649 data ${ }^{145-147}$. A triangular relationship was supported when the regressions through the $95 \%$ and $6505 \%$ quantiles differed according to $t$-tests.

\section{Comparative analyses}

653 Comparative phylogenetic statistical analyses accounting for the effects of phylogenetic 654 covariance on trait-climate and trait-trait relationships were conducted using the R Language and 655 Environment version 3.4.1 ${ }^{130}$.

656 Regression coefficients were estimated using phylogenetic least squares (PGLS) and/or 657 phylogenetic reduced major axis (PRMA), in each case basing the phylogenetic correction on 658 Pagel's $\lambda^{148,149}$ estimated by maximum likelihood ${ }^{150}$. For PGLS, corPagel ${ }^{151}$ was used in 659 combination with gls ${ }^{150}$ and optimized ${ }^{131}$ to establish maximum likelihood estimates of $\lambda$ in the 0 $660-1$ range; for PRMA, phyl.RMA ${ }^{151}$ was used. Confidence intervals for $b$ estimated using PRMA 661 were determined following $\operatorname{ref}^{152}$ :

$$
\pm \hat{b}(\sqrt{B+1} \pm \sqrt{B}), \text { where } B=\frac{1-r^{2}}{N-2} f_{1-\alpha, 1, N-2}
$$

662 where $\hat{b}$ is the fitted value for $b ; r$ is a correlation coefficient, for which we used a 663 phylogenetically corrected estimate based on the variance-covariance matrix output by 664 phyl.RMA; $N$ is the number of pairs of observations; and $f_{1-\alpha, 1, N-2}$ is the critical value from the 665 F distribution.

666 Differences in species-level trait means between $\mathrm{C}_{3}$ and $\mathrm{C}_{4}$ species were tested using a 667 phylogenetically corrected ANOVA, both parametric (based on phylogenetic generalized least 668 squares analysis, PGLS) and nonparametric ${ }^{153}$; phyloANOVA in R package $^{151}$. 
670 with Pagel's $\lambda$ estimated by maximum likelihood, to equivalent models in which Pagel's $\lambda$ was 671 set to 0 . When using Pagel's $\lambda$, to assess normality and homoscedasticity assumptions we first 672 extracted phylogenetic residuals. For PGLS, the function residuals was used to extract 673 normalized residuals; for PRMA, a custom code (available on request), derived from an original 674 provided by Professor Robert P. Freckleton, was used to produce an equivalent transformation of 675 raw residuals obtained from phyl.RMA. Normality was tested using Anderson Darling tests ${ }^{154}$ 676 and heteroscedasticity using Bartlett's test ${ }^{130}$. Additionally, PGLS was used to estimate Pagel's $\lambda$ 677 for phylogenetic residuals, which should be 0 .

678 The PGLS and PRMA approaches used to test for scaling relationships of vein traits with 679 leaf dimensions and to estimate the slopes of linearized power law relationships are phylogenetic 680 approaches equivalent to ordinary least squares and reduced major axis regressions, respectively. 681 Which of the two was used depended on the specific relationship tested. The least squares 682 approach is preferable in cases when a dependent $\mathrm{Y}$ variable is related to an independent $\mathrm{X}$ 683 variable, specifically when (1) there is much less error (i.e., natural variation and/or 684 measurement error) in $\mathrm{X}$ than $\mathrm{Y}$, and/or when (2) conceptually, $\mathrm{Y}$ is causally determined by, or 685 to be predicted from, $\mathrm{X}$, but never $\mathrm{X}$ from $\mathrm{Y}^{155,156}$. By contrast, the reduced major axis approach 686 is preferable in cases when (1) X and Y have similar error, and/or when (2) X or Y are co687 determined, or their relationship arises from an underlying functional coordination, or either 688 could reasonably be predicted using the other; this approach is typically used in studies of 689 allometric scaling relationships among functional traits or organ dimensions ${ }^{155,156}$. An exception 690 to the use of reduced major axis for allometry is when testing whether the allometric slope of a 691 relationship is consistent with an expected slope that was derived algebraically from other 692 equations, as only least-squares slopes are robust to algebraic manipulation ${ }^{156}$. For example, 693 PGLS would be selected over PRMA to test an expectation for the scaling slope of vein surface 694 area per leaf area (VSA) with leaf length, that was derived algebraically by multiplying the 695 expected scaling slopes of vein length per area (VLA) and vein diameter (VD) with leaf length, 696 given that VSA is determined from VLA and VD (see, "Quantification of leaf dimensions and 697 vein traits", above). Further, while least squares is appropriate for testing relationships of a 698 dependent versus an independent trait, reduced major axis can be preferable for illustrating the 
relationship in a plot, given that it captures more closely the central trend among two variables with high and/or similar error ${ }^{155,156}$.

Thus, we selected PGLS or PRMA for the tested relationships according to which was most appropriate given the above principles, while noting that the application of any single approach globally would not affect the findings of the study, but would reduce the accuracy of the specific slope estimates. We used PRMA to test relationships of traits with climate variables, as the magnitude of variation in modelled climate variables globally was similar to that for species means for leaf traits. We also used PRMA for testing scaling relationships of vein diameters with leaf length and width, and of xylem conduit diameters with vein diameters, given the preference of this approach for testing allometric relationships, and the similar error in the $\mathrm{X}$ and Y variables. We used PGLS for testing relationships of vein lengths, surface areas and volumes per leaf area with leaf dimensions, given the higher variability in the vein traits than leaf

711 dimensions arising due to their determination from one or more vein traits as well as leaf 712 dimensions (e.g., vein length per leaf area = vein number / leaf width). Further, PGLS was most 713 appropriate for testing allometric slopes for the relationships of vein traits to leaf area, because

714 the expectations for these slopes from the developmental model were derived algebraically from 715 expected slopes of vein traits in relation to leaf length and leaf width ${ }^{155}$. Finally, we used PRMA 716 in all figure plots to most clearly illustrate the central trends accounting for phylogeny ${ }^{155,156}$.

717 Lastly, we evaluated whether the scaling of vein traits with leaf dimensions differed 718 between $\mathrm{C}_{3}$ and $\mathrm{C}_{4}$ species. $\mathrm{C}_{3}$ and $\mathrm{C}_{4}$ species were considered to differ significantly in trait-trait 719 or trait-climate associations if significant relationships were found independently for both 720 groups, and if there was no overlap in scaling slope 95\% confidence intervals (CIs) using the 721 selected regression approach (PGLS or PRMA).

723 Modelling the impacts of leaf energy budget and testing hypotheses for the benefits of 724 smaller leaves under different climates

725 We considered three hypotheses for the advantage of small leaf sizes in cold or dry climates 726 based on their thinner boundary layer. Smaller leaves have been hypothesized to (1) experience 727 less damage under extreme temperatures, i.e. chilling on colds nights and overheating on hot 728 days $^{3,157,158}$, (2) maintain higher rates of photosynthesis and/or higher leaf water use efficiency in 729 cold and/or dry conditions ${ }^{19,20}$ and (3) achieve higher gas exchange in favorable, warm and wet 
730 climates $^{4}$, which would provide an advantage in mitigating the shorter diurnal and/or seasonal 731 growing periods of cold or dry climates.

732 To test hypothesis (1), i.e., that small grass leaves are typical in cold or dry climates 733 globally because they avoid extreme temperatures, we calculated the minimum threshold of leaf 734 size for chilling or overheating. We used the $100 \mathrm{~cm}^{2}$ leaf size threshold for damage by nighttime 735 chilling and $30 \mathrm{~cm}^{2}$ for damage by daytime overheating, i.e., the lowest thresholds that were 736 modelled for eudicotyledons globally given in Fig. 3 of ref. 3. Those leaf size thresholds for 737 eudicotyledons were derived from estimated damage thresholds based on the "characteristic 738 dimension" of the leaf ( $d$, i.e., the diameter of the largest circle that can be delimited within a 739 leaf) of $8.16 \mathrm{~cm}$ and $4.47 \mathrm{~cm}$, according to eqn 4 in the supplemental information of ref 3 (LA = $7401.5 d^{2}$ ). Thus, we used these threshold values to exclude species with leaf width $<8.16 \mathrm{~cm}$ and $<$ $7414.47 \mathrm{~cm}$, and then tested whether the observed trends of leaf dimensions with MAT and MAP 742 globally remained. Significant trends for this restricted species set would indicate that thresholds 743 for leaf damage under extreme temperatures cannot explain trends for grasses with leaves 744 smaller than those thresholds. By testing trends against these very low thresholds, we provided a 745 very conservative test to establish that avoidance of extreme temperatures would not explain the 746 global climatic distribution of grass leaf size.

747 To test hypotheses (2) and (3), we used heuristic leaf energy balance modelling to 748 simulate the consequences for gas exchange of leaf sizes varying in size ${ }^{159}$. Using the Tealeaves $749 \mathrm{R}$ package ${ }^{159}$, given inputs of leaf width, wind speed, stomatal conductance and air temperature, 750 we simulated boundary layer conductance, leaf temperature, and transpiration rate. To represent 751 the bulk of the global range of grass leaf size, we focused on comparing the global $5^{\text {th }}$ and $95^{\text {th }}$ 752 quantiles of leaf width $(0.1 \mathrm{~cm}$ and $2.7 \mathrm{~cm})$. We simulated leaves in wet and dry conditions by 753 setting stomatal conductance values at $0.4 \mathrm{~mol} \mathrm{~m}^{-2} \mathrm{~s}^{-1}$ and $0.2 \mathrm{~mol} \mathrm{~m}^{-2} \mathrm{~s}^{-1}$, respectively ${ }^{160}$; our 754 tests showed that selecting other values would yield similar qualitative results. To represent 755 warm and cold climates we simulated gas exchange under air temperatures of $315 \mathrm{~K}$ and $280 \mathrm{~K}$ $756\left(41.85{ }^{\circ} \mathrm{C} \text { and } 6.85{ }^{\circ} \mathrm{C} \text { respectively }\right)^{161}$. All other physical and environmental inputs were 757 maintained constant at typical values ${ }^{159}$. We used the output values of leaf temperature and 758 boundary layer conductance to simulate $\mathrm{C}_{3}$ photosynthetic rate for leaves of different widths 759 using the Farquhar model ${ }^{162,163}$. We tested these effects at the two wind speeds, $0.1 \mathrm{~m} / \mathrm{s}$ and 2 $760 \mathrm{~m} / \mathrm{s}$. Lastly, we tested simulations for both amphistomatous and hypostomatous leaves, and we 
761 present results for amphistomatous leaves given that most grasses are amphistomatous ${ }^{164}$. To test 762 for the potential benefit of smaller leaves, we calculated the ratios of photosynthetic rate, 763 transpiration and leaf water use efficiency for a small relative to large leaf; values $>1$ indicate an 764 advantage for the small leaf in cold or dry conditions. To test for the potential benefit of smaller 765 leaves in mitigating a shorter period with favourable climate, we calculated the ratios of 766 photosynthetic rate, transpiration and leaf water use efficiency under warm and wet conditions 767 for a small versus a large leaf; again, values $>1$ signify a small leaf advantage.

769 Supplementary References

48 Kluyver, T. A. \& Osborne, C. P. Taxonome: a software package for linking biological 772 species data. Ecol. Evol. 3, 1262-1265 (2013).

50 Fick, S. E. \& Hijmans, R. J. WorldClim 2: new 1-km spatial resolution climate surfaces for global land areas. Int J. Climatol. 37, 4302-4315 (2017). Cayuela, L., Granzow-de la Cerda, I., Albuquerque, F. S. \& Golicher, D. J. TAXONSTAND: An $\mathrm{R}$ package for species names standardisation in vegetation databases. Methods Ecol. Evol. 3, 1078-1083 (2012). Cherlet, M. H., C.; Reynolds, J.; Hill, J.; Sommer, S.; von Maltitz, G. World Atlas of Desertification. 3rd edn, (Publication Office of the European Union, 2018).

52 Harris, I., Jones, P. D., Osborn, T. J. \& Lister, D. H. Updated high-resolution grids of monthly climatic observations - the CRU TS3.10 Dataset. Int. J. Climatol. 34, 623-642 (2014).

53 Lasky, J. R. et al. Characterizing genomic variation of Arabidopsis thaliana: the roles of geography and climate. Mol. Ecol. 21, 5512-5529 (2012).

4 Sexton, J. P., McIntyre, P. J., Angert, A. L. \& Rice, K. J. Evolution and Ecology of Species Range Limits. Ann. Rev. Ecol. Evol. \& Syst. 40, 415-436 (2009).

55 Dengler, N. G., Dengler, R. E. \& Hattersley, P. W. Differing ontogenetic origins of PCR (Kranz) sheaths in leaf blades of $\mathrm{C}_{4}$ grasses (Poaceae). Am. J. Bot. 72, 284-302 (1985).

56 Dengler, N. G., Woodvine, M. A., Donnelly, P. M. \& Dengler, R. E. Formation of vascular pattern in developing leaves of the $\mathrm{C}_{4}$ grass Arundinella hirta. Int. J. Plant Sci. 158, 1-12 (1997). 
79257 Ikenberry, G.-J. J. Developmental vegetative morphology of avena sativa $\mathrm{PhD}$ thesis, 793 Iowa State University, (1959).

79458 Kaufman, P. B. \& Brock, T. G. Structural development of the oat plant. Agronomy $795 \quad$ Monograph 33, 53 - 75 (1992).

79659 Hitch, P. A. \& Sharman, B. C. Initiation of procambial strands in leaf primordia of 797 Dactylis glomerata $L$ as an example of a temperate herbage grass. Ann. Bot-London 32, 153-164 (1968).

Davidson, J. L. \& Milthorpe, F. L. Leaf growth in Dactylis glomerata following 61 Volenec, J. J. \& Nelson, C. J. Cell dynamics in leaf meristems of contrasting tall fescue genotypes. Crop Sci 21, 381-385 (1981).

63 Macadam, J. W., Volenec, J. J. \& Nelson, C. J. Effects of nitrogen on mesophyll cell division and epidermal cell elongation in tall fescue leaf blades. Plant Physiol. 89, 549556 (1989).

64 Skinner, R. H. \& Nelson, C. J. Elongation of the grass leaf and its relationship to the phyllochron. Crop Sci. 35, 4-10 (1995).

65 Skinner, R. H. \& Nelson, C. J. Epidermal cell division and the coordination of leaf and tiller development. Ann. Bot-London 74, 9-15 (1994).

66 Maurice, I., Gastal, F. \& Durand, J. L. Generation of form and associated mass deposition during leaf development in grasses: a kinematic approach for non-steady growth. Ann. Bot-London 80, 673-683 (1997).

67 Durand, J. L., Schaufele, R. \& Gastal, F. Grass leaf elongation rate as a function of developmental stage and temperature: Morphological analysis and modelling. Ann. BotLondon 83, 577-588 (1999).

68 Martre, P., Durand, J. L. \& Cochard, H. Changes in axial hydraulic conductivity along elongating leaf blades in relation to xylem maturation in tall fescue. New Phytol. 146, 235-247 (2000). 
82169 Martre, P. \& Durand, J. L. Quantitative analysis of vasculature in the leaves of Festuca 822 arundinacea (Poaceae): Implications for axial water transport. Int. J. Plant Sci. 162, 755$823 \quad 766(2001)$.

82470 Gallagher, J. N. Field studies of cereal leaf growth 1. Initiation and expansion in relation 825 to temperature and ontogeny. J Exp Bot 30, 625-636 (1979).

82671 Gallagher, J. N. \& Biscoe, P. V. Field studies of cereal leaf growth 3. Barley leaf 827 extension in relation to temperature, orradiance, and water potential. J. Exp. Bot. 30, 645$828 \quad 655(1979)$.

82972 Dannenhoffer, J. M., Ebert, W. \& Evert, R. F. Leaf vasculature in barley, Hordeum $830 \quad$ vulgare (Poaceae). Am. J. Bot. 77, 636-652 (1990).

83173 Dannenhoffer, J. M. \& Evert, R. F. Development of the vascular system in the leaf of barley (Hordeum vulgare L). Int. J. Plant Sci. 155, 143-157 (1994).

83374 Trivett, C. L. \& Evert, R. F. Ontogeny of the vascular bundles and contiguous tissues in 834 the barley leaf blade. Int. J. Plant Sci. 159, 716-732 (1998).

83575 Soper, K. \& Mitchell, K. J. The developmental anatomy of perennial ryegrass (Lolium 836 perenne L.). NZ J. Sci. Tech. 37, 484-504 (1956).

83776 Schnyder, H., Nelson, C. J. \& Coutts, J. H. Assessment of spatial distribution of growth 838 in the elongation zone of grass leaf blades. Plant Physiol. 85, 290-293 (1987).

83977 Arredondo, J. T. \& Schnyder, H. Components of leaf elongation rate and their 840 relationship to specific leaf area in contrasting grasses. New Phytol. 158, 305-314 (2003).

84178 Kaufman, P. B. Development of the shoot of Oryza sativa L. - II. Leaf histogenesis. Phytomorphology 9, 277-311 (1959).

84379 Yamazaki, K. Studies on the leaf formation in rice plants: I. Observation on the $844 \quad$ successive development of the leaf. Jap. J. Crop Sci. 31, 371-378 (1963).

84580 Chonan, N. K., H.; Matsuda, T. Morphology on vascular bundles of leaves in gramineous 846 crops: I. Observations on vascular bundles of leaf blades, sheaths and internodes in 847 riceplants. Jap. J. Crop Sci. 43, 425-432 (1974).

$848 \quad 81$ Hoshikawa, K. The growing rice plant: an anatomical monograph. (Nobunkyo, 1989).

84982 Matsukura, C. et al. Transverse vein differentiation associated with gas space formation $850 \quad$ Fate of the middle cell layer in leaf sheath development of rice. Ann. Bot-London 85, 19$85127(2000)$. 
85283 Itoh, J. et al. Rice plant development: from zygote to spikelet. Plant Cell Physiol. 46, 2385347 (2005).

85484 Sakaguchi, J. \& Fukuda, H. Cell differentiation in the longitudinal veins and formation of $855 \quad$ commissural veins in rice (Oryza sativa) and maize (Zea mays). J. Plant Res. 121, 593$856 \quad 602(2008)$.

85785 Parent, B., Conejero, G. \& Tardieu, F. Spatial and temporal analysis of non-steady 858 elongation of rice leaves. Plant Cell Environ. 32, 1561-1572 (2009).

85986 Begg, J. E. \& Wright, M. J. Growth and development of leaves from intercalary meristems in Phalaris arundinacea L. Nature 194, 1097-1098 (1962). Colbert, J. T. \& Evert, R. F. Leaf vasculature in sugarcane (Saccharum officinarum L). Planta 156, 136-151 (1982).

Bernstein, N., Silk, W. K. \& Lauchli, A. Growth and development of sorghum leaves under conditions of $\mathrm{NaCl}$ stress - Spatial and temporal aspects of leaf growth inhibition. Planta 191, 433-439 (1993).

89 Sud, R. M. \& Dengler, N. G. Cell lineage of vein formation in variegated leaves of the $\mathrm{C}_{4}$ grass Stenotaphrum secundatum. Ann. Bot-London 86, 99-112 (2000).

90 Sharman, B. C. \& Hitch, P. A. Initiation of procambial strands in leaf primordia of bread wheat Triticum aestivum L. Ann. Bot-London 31, 229-243 (1967). Blackman, E. The morphology and development of cross veins in the leaves of bread wheat (Triticum aestivum L.). Ann. Bot-London 35, 653-665 (1971).

88196 Esau, K. Ontogeny of the vascular bundle in Zea mays. Hilgardia 15, 327-368 (1943). 
88297 Bosabalidis, A. M., Evert, R. F. \& Russin, W. A. Ontogeny of the vascular bundles and 883 contiguous tissues in the maize leaf blade. Am. J. Bot. 81, 745-752 (1994).

88498 Poethig, S. in Contemporary problems in plant anatomy (ed R. A.; Dickison White, W. 885 C.) (Academic Press, 1984).

88699 Russell, S. H. \& Evert, R. F. Leaf Vasculature in Zea mays-L. Planta 164, 448-458 (1985).

888100 Smith, L. G., Greene, B., Veit, B. \& Hake, S. A dominant mutation in the maize 889 homeobox gene, knotted-1, causes its ectopic expression in leaf-cells with altered fates. Development 116, 21-\& (1992).

101 Fournier, C. \& Andrieu, B. A 3D architectural and process-based model of maize

102 Muller, B., Reymond, M. \& Tardieu, F. The elongation rate at the base of a maize leaf

103 Muller, B. et al. Association of specific expansins with growth in Maize leaves is maintained under environmental, genetic, and developmental sources of variation. Plant Physiol. 143, 278-290 (2007).

104 Johnston, R., Leiboff, S. \& Scanlon, M. J. Ontogeny of the sheathing leaf base in maize (Zea mays). New Phytol. 205, 306-315 (2015).

106 Tardieu, F., Reymond, M., Hamard, P., Granier, C. \& Muller, B. Spatial distributions of expansion rate, cell division rate and cell size in maize leaves: a synthesis of the effects of soil water status, evaporative demand and temperature. J. Exp. Bot. 51, 1505-1514 (2000).

107 Runions, A. et al. Modeling and visualization of leaf venation patterns. Acm T. Graphic

910108 Scarpella, E. \& Meijer, A. H. Pattern formation in the vascular system of monocot and 911 dicot plant species. New Phytol. 164, 209-242 (2004). 
912109 Baskin, T. I. Anisotropic expansion of the plant cell wall. Ann. Rev. Cell. Dev. 21, 203$913222(2005)$.

914110 Fujita, H. \& Mochizuki, A. The origin of the diversity of leaf venation pattern. Dev. Dyn. $915 \quad 235,2710-272(2006)$.

916111 Granier, C. \& Tardieu, F. Multi-scale phenotyping of leaf expansion in response to 917 environmental changes: the whole is more than the sum of parts. Plant Cell Environ. 32, 918 1175-1184 (2009).

919112 Scarpella, E., Barkoulas, M. \& Tsiantis, M. Control of leaf and vein development by auxin. Csh Perspect Biol 2 (2010).

921113 Gazquez, A. \& Beemster, G. T. S. What determines organ size differences between 922 species? A meta-analysis of the cellular basis. New Phytol. 215, 299-308 (2017).

923114 Scarpella, E. The logic of plant vascular patterning. Polarity, continuity and plasticity in 924 the formation of the veins and of their networks. Curr. Opin. Genet. Dev. 45, 34-43 925 (2017).

926115 Berlyn, G. P. M., J. P. Botanical Microtechnique and Cytochemistry. (Iowa State $927 \quad$ University Press, 1976).

928116 Kemp, C. D. Methods of estimating leaf area of grasses from linear measurements. New. 929 Phytol. 24, 491-299 (1960).

930117 Stickler, F. C., Wearden, S. \& Pauli, A. W. Leaf area determination in grain sorghum. 931 Agronony 53, 187-188 (1961).

932118 Shi, P. et al. Leaf area-length allometry and its implications in leaf shape evolution. 933 Trees 33, 1073-1085 (2019).

934119 Ellis, R. P. A procedure for standardizing comparative leaf anatomy in the Poaceae. I. 935 The leaf blade as viewed in transverse section. Bothalia 12, 65-109 (1976).

936120 Evert, R. F. Esau's plant anatomy: meristems, cells, and tissues of the plant body: their 937 structure, function, and development. (John Wiley \& Songs, 2006).

938121 Neufeld, H. S. et al. Genotypic variability in vulnerability of leaf xylem to cavitation in 939 water-stressed and well-irrigated sugarcane. Plant Physiol. 100, 1020-1028 (1992).

940122 Tyree, M. T., Zimmermann, M. H. \& Zimmermann, M. H. Xylem structure and the $941 \quad$ ascent of sap. 2nd edn, (Springer, 2002).

942123 Wright, I. J. et al. The world-wide leaf economics spectrum. Nature 428, 821-827 (2004). 
943124 Aliscioni, S. et al. New grass phylogeny resolves deep evolutionary relationships and 944 discovers $\mathrm{C}_{4}$ origins. New Phytol. 193, 304-312 (2012).

945125 Taylor, S. H. et al. Photosynthetic pathway and ecological adaptation explain stomatal 946 trait diversity amongst grasses. New Phytol. 193, 387-396 (2012).

947126 Edgar, R. C. MUSCLE: multiple sequence alignment with high accuracy and high

127 Drummond, A. J. \& Rambaut, A. BEAST: Bayesian evolutionary analysis by sampling $950 \quad$ trees. Bmc Evol Biol 7 (2007).

951128 Christin, P. A. et al. Molecular Dating, Evolutionary Rates, and the Age of the Grasses. $952 \quad$ Syst Biol 63, 153-165 (2013).

953129 Prasad, V. et al. Late Cretaceous origin of the rice tribe provides evidence for early

130 R: A language and environment for statistical computing (R Foundation for Statistical 956 Computing, Vienna, Austria, 2019).

957131 Paradis, E. \& Schliep, K. ape 5.0: an environment for modern phylogenetics and 958 evolutionary analyses in R. Bioinformatics 35, 526-528(2019).

959132 Spriggs, E. L., Christin, P. A. \& Edwards, E. J. (ed Dryad Digital Repository) (2014).

960133 Felsenstein, J. Phylogenies and the comparative method. Am. Nat. 125, 1-15 (1985).

961134 Schmerler, S. B. et al. Evolution of leaf form correlates with tropical-temperate 962 transitions in Viburnum (Adoxaceae). P. Royal. Soc. B. 279, 3905-3913 (2012).

963135 Fletcher, L. R. et al. Evolution of leaf structure and drought tolerance in species of 964 Californian Ceanothus. Am. J. Bot. 105, 1672-1687 (2018).

965136 Bramer, I. et al. in Next Generation Biomonitoring: Part 1: Advances in Ecological 966 Research 101-161 (2018).

967137 Zanne, A. E. et al. Three keys to the radiation of angiosperms into freezing environments. $968 \quad$ Nature 514, 394-394 (2014).

969138 Watcharamongkol, T., Christin, P. A. \& Osborne, C. P. C 4 photosynthesis evolved in $970 \quad$ warm climates but promoted migration to cooler ones. Ecol. Lett. 21, 376-383 (2018).

971139 Burnham, K. P. \& Anderson, D. R. Model selection and multimodel inference. 2 edn, $972 \quad$ (Springer, 2002). 
973140 Gelman, A. \& Hill, J. Data analysis using regression and multilevel/hierarchical models. 974 (Cambridge University Press, 2006).

975141 Faraway, J. J. Linear Models with R. (Chapman \& Hall/CRC, 2009).

976142 Murray, K. \& Conner, M. M. Methods to quantify variable importance: implications for 977 the analysis of noisy ecological data. Ecology 90, 348-355 (2009).

978143 Westoby, M. \& Wright, I. J. Land-plant ecology on the basis of functional traits. Trends $979 \quad$ Ecol. Evol. 21, 261-268 (2006).

980144 Grubb, P. J. Trade-offs in interspecific comparisons in plant ecology and how plants 981 overcome proposed constraints. Plant Ecol. Divers. 9, 3-33 (2016).

982145 Cade, B. S. \& Noon, B. R. A gentle introduction to quantile regression for ecologists. 983 Front. Ecol. Environ. 1, 412-420 (2003).

984146 Grubb, P. J., Coomes, D. A. \& Metcalfe, D. J. Comment on "A Brief History of Seed $985 \quad$ Size". Science 310, $781-783$ (2005).

986147 Moles, A. T. et al. Global patterns in plant height. J. Ecol. 97, 923-932 (2009).

987148 Pagel, M. Inferring the historical patterns of biological evolution. Nature 401, 877-884 $988 \quad$ (1999).

989149 Freckleton, R. P., Harvey, P. H. \& Pagel, M. Phylogenetic analysis and comparative data: $990 \quad$ A test and review of evidence. Am. Nat. 160, 712-726 (2002).

$991 \quad 150 \quad$ "nlme" (R package version 3.1-140) (2019).

992151 Revell, L. J. phytools: an R package for phylogenetic comparative biology (and other 993 things). Methods Ecol. Evol. 3, 217-223 (2012).

994152 Warton, D. I., Wright, I. J., Falster, D. S. \& Westoby, M. Bivariate line-fitting methods 995 for allometry. Biol. Rev. 81, 259-291 (2006).

996153 Garland, T., Dickerman, A. W., Janis, C. M. \& Jones, J. A. Phylogenetic Analysis of 997 Covariance by Computer-Simulation. Syst. Biol. 42, 265-292 (1993).

998154 "nortest: Tests for normality" (R package version 1.0-4) (2015).

999155 Poorter, H. \& Sack, L. Pitfalls and possibilities in the analysis of biomass allocation 1000 patterns in plants. Front. Plant Sci. 3, 1-10 (2012).

1001156 Smith, R. J. Use and Misuse of the Reduced Major Axis for Line-Fitting. Am. J. Phys. 1002 Anthropol. 140, 476-486 (2009).

1003157 Gates, D. M. Energy, Plants, and Ecology. Ecology 46, 1-13 (1965). 
1004158 Lusk, C. H. et al. Frost and leaf-size gradients in forests: global patterns and experimental 1005 evidence. New Phytol. 219, 565-573 (2018).

1006159 Muir, C. D. tealeaves: an R package for modelling leaf temperature using energy budgets. 1007 Aob Plants 11, 1-10 (2019).

1008160 Taylor, S. H. et al. Ecophysiological traits in $\mathrm{C}_{3}$ and $\mathrm{C}_{4}$ grasses: a phylogenetically 1009 controlled screening experiment. New Phytol. 185, 780-791 (2010).

1010161 Huang, M. et al. Air temperature optima of vegetation productivity across global biomes. $1011 \quad$ Nat. Ecol. Evol. 3, $772-779$ (2019).

1012162 Farquhar, G. D., Caemmerer, S. V. \& Berry, J. A. A biochemical model of photosynthetic $1013 \quad \mathrm{CO}_{2}$ assimilation in leaves of $\mathrm{C}_{3}$ species. Planta 149, 78-90 (1980).

1014163 Bernacchi, C. J., Pimentel, C. \& Long, S. P. In vivo temperature response functions of 1015

1016

1017164 Muir, C. D. Making pore choices: repeated regime shifts in stomatal ratio. P. Royal. Soc. 1018 B. 282, 1-9 (2012).

1019165 Brummitt, R. K. World geographical scheme for recording plant distributions. (2001).

1020166 Redmann, R. E. Adaptation of grasses to water-stress - leaf rolling and stomate 1021 distribution. Ann. Mo. Bot. Gard. 72, 833-842 (1985).

1022167 Forrestel, E. J. et al. Different clades and traits yield similar grassland functional 1023 responses. P. Natl. Acad. Sci. USA 114, 705-710 (2017).

1024168 Liu, H., Edwards, E. J., Freckleton, R. P. \& Osborne, C. P. Phylogenetic niche 1025 conservatism in $\mathrm{C}_{4}$ grasses. Oecologia 170, 835-845 (2012).

1026169 Liu, H. \& Osborne, C. P. Water relations traits of $\mathrm{C}_{4}$ grasses depend on phylogenetic 1027 lineage, photosynthetic pathway, and habitat water availability. J. Exp. Bot. 66, 761-773 1028 (2015).

1029170 Jardine, E. C., Thomas, G. H., Forrestel, E. J., Lehmann, C. E. R. \& Osborne, C. P. The 1030 global distribution of grass functional traits within grassy biomes. J. Biogeogr. 47, 553$1031565(2020)$.

1032171 Kawai, K. \& Okada, N. Leaf vascular architecture in temperate dicotyledons: correlations 1033 and link to functional traits. Planta 251, 1-12 (2019). 
1034172 Medeiros, C. D. et al. An extensive suite of functional traits distinguishes Hawaiian wet and dry forests and enables prediction of species vital rates. Funct. Ecol. 33, 712-734 (2019).

$1037173 \mathrm{Li}$, F. L. et al. Linking leaf hydraulic properties, photosynthetic rates, and leaf lifespan in

174 Blackman, C. J. et al. The links between leaf hydraulic vulnerability to drought and key

175 Gleason, S. M. et al. Vessel scaling in evergreen angiosperm leaves conforms with Murray's law and area-filling assumptions: implications for plant size, leaf size and cold tolerance. New Phytol. 218, 1360-1370 (2018).

177 Brodribb, T. J., Bienaime, D. \& Marmottant, P. Revealing catastrophic failure of leaf

178 Schneider, J. V. et al. Water supply and demand remain coordinated during breakdown of

179 Coomes, D. A., Heathcote, S., Godfrey, E. R., Shepherd, J. J. \& Sack, L. Scaling of 1053 xylem vessels and veins within the leaves of oak species. Biol. Letters 4, 302-306 (2008).

181 McKown, A. D., Akamine, M. E. \& Sack, L. Trait convergence and diversification 1058

182 Kawai, K. \& Okada, N. How are leaf mechanical properties and water-use traits 1061

1062 coordinated by vein traits? A case study in Fagaceae. Funct. Ecol. 30, $527-536$ (2016).

183 Dunbar-Co, S., Sporck, Margaret J. \& Sack, L. Leaf Trait diversification and design in seven rare taxa of the hawaiian plantago radiation. Int. J. Plant Sci. 170, 61-75 (2009). 
1064184 Scoffoni, C. et al. Light-induced plasticity in leaf hydraulics, venation, anatomy, and gas exchange in ecologically diverse Hawaiian lobeliads. New Phytol.. 207, 43-58 (2015).

$1066185 \mathrm{Lu}, \mathrm{Z}$. et al. Potassium mediates coordination of leaf photosynthesis and hydraulic conductance by modifications of leaf anatomy. Plant Cell Environ. 42, 2231-2244 (2019).

1070

187 Brocious, C. A. \& Hacke, U. G. Stomatal conductance scales with petiole xylem traits in Populus genotypes. Funct. Plant Biol. 43, 553-562 (2016).

188 Mauri, R. et al. Leaf hydraulic properties are decoupled from leaf area across coffee

189 Nardini, A., Ounapuu-Pikas, E. \& Savi, T. When smaller is better: leaf hydraulic conductance and drought vulnerability correlate to leaf size and venation density across four Coffea arabica genotypes. Funct. Plant Biol. 41, 972-982 (2014).

190 Mediavilla, S., Martín, I. \& Escudero, A. Vein and stomatal traits in leaves of three cooccurring Quercus species differing in leaf life span. Eur. J. For. Res. 139, 829-840 (2020).

191 Wang, J.-H., Cai, Y.-F., Li, S.-F. \& Zhang, S.-B. Photosynthetic acclimation of 1083 rhododendrons to light intensity in relation to leaf water-related traits. Plant Ecol. 221, 407-420 (2020).

192 Cardoso, A. A. et al. Extended differentiation of veins and stomata is essential for the 1088

194 Sevanto, S., Holbrook, N. M. \& Ball, M. C. Freeze/Thaw-Induced embolism: probability 1090 of critical bubble formation depends on speed of ice formation. Front. Plant Sci. 3, 1-12 (2012). expansion of large leaves in Rheum rhabarbarum. Am. J. Bot. 105, 1967-1974 (2018).

3 Taneda, H. \& Terashima, I. Co-ordinated development of the leaf midrib xylem with the lamina in Nicotiana tabacum. Ann. Bot. 110, 35-45 (2012). 
196 Spriggs EL, Christin P-A, Edwards EJ (2014) $\mathrm{C}_{4}$ Photosynthesis promoted species diversification during the miocene grassland expansion. PloS One 9, 1-10 (2014).

\section{Acknowledgments}

1099 We thank T Cheng, W Deng, A.C. Diener, A Kooner, M McMaster, C Muir, S Moshrefi, A. J.

1100 Patel, A Sayari and M. S. Vorontsova for logistical assistance. Funding: Funding was provided 1101 by the U.S. National Science Foundation (grants 1457279, 1951244 and 2017949), the Natural 1102 Environment Research Council (grants NE/DO13062/1 and NE/T000759/1) and a Royal Society 1103 University Research Fellowship (grant URF\R\180022).

\section{Author contributions} Conceptualization: ASB, SHT, CPO, LS; Data curation \& Writing - review \& editing: ASB,

1108 TW, CS, PAC, LS; Funding acquisition: CPO, LS; Investigation: ASB, SHT, JPK, TW, CS, 1109 EJE, PAC, CPO, LS; Methodology: ASB, SHT, JPK, TW, CS, EJE, PAC, CPO, LS; Project 1110 administration: ASB, SHT, JPK, CPO, LS Resources: ASB, SHT, JPK, TW, CS, EJE, PAC, 1111 CPO, LS; Software: ASB, SHT, TW, PAC; Supervision: ASB, SHT, JPK, CPO, LS; Validation: 1112 ASB, SHT, CPO, LS; Visualization: ASB, SHT, TW, CV, PAC; Writing - original draft: ASB, 1113 SHT, LS

\section{Competing interests}

1116 We declare no competing interests. All data are available in the main text or supplementary 1117 materials.

\section{Additional information}

1120 Supplementary information is available online. Reprints and permissions information is available 1121 online at www.nature/com/reprints. Correspondence and requests for materials should be 1122 addressed to A.S.B. 


\section{Data availability}

1127 Data utilized in this study are provided in the supplementary materials. Leaf trait data for the

11281752 grass species was provided by the published Kew Grassbase Database

1129 (http://www.kew.org/data/grassbase/). Species' climate data were extracted from WorldClim 2 5-

1130 arc minute resolution (https://worldclim.org/version2) and from CRU TS4.01 01

1131 (https://crudata.uea.ac.uk/cru/data/hrg/cru_ts_4.01/) based on each species' geographical records

1132 (http://www.gbif.org). Photosynthetic trait data and field locations were extracted for the $13 \mathrm{C}_{3}$

1133 grass species for which this was available in GLOPNET

1134 (http://bio.mq.edu.au/ iwright/glopian.htm).

1136 Code availability

1137 Custom-written R code is available on GitHub (https:/github.com/smuel-tylor/grass-leaf-size-).

1139 Extended Data Figure Legends

Extended Data Fig. 1 Time-calibrated phylogenetic trees for 1752 worldwide grass species and for 27 grass species grown in a greenhouse common garden. (a) phylogeny for 1752 species trimmed from that of reference 196 and used for analyses of global scaling of leaf size

1144 with climate. $C_{3}$ and $C_{4}$ species in black and red respectively ( $n=840$ and $n=912$ respectively).

1145 (b) phylogeny for 27 species used for analyses of leaf vein scaling (black branches $=11 \mathrm{C}_{3}$, red 1146 branches $=16 \mathrm{C}_{4}$ ), emphasizing the inclusion of 11 independent $\mathrm{C}_{4}$ origins. World map with 1147 distributions of (c) $11 \mathrm{C}_{3}$ species and, (d) $16 \mathrm{C}_{4}$ species.

Extended Data Fig. 2. Worldwide relationships of grass leaf and plant dimensions with species' native climate, the global distribution of grass leaf size, and the scaling of grass leaf

1151 and plant dimensions. Relationships of (a) - (c) Leaf length, (d) - (f) leaf width, (g) - (i) leaf 1152 area, and (j) - (l) culm height with mean annual temperature (MAT, $\left.{ }^{\circ} \mathrm{C}\right)$, mean annual 1153 precipitation (MAP, mm) and aridity index (AI). (m-o) Average across species of leaf area for 1154 each country in the global database (International Working Group on Taxonomic Databases for 1155 Plant Sciences, TDWG level 3 spatial units ${ }^{168}$ ), including countries for which $>20$ species occur 1156 in the global database $(21-547$ species for each country; gray for countries with $<20$ species 
1157 represented), i.e., (m) mean leaf area (n) median leaf area and (o) leaf area for the largest leafed 1158 species (p) The scaling of leaf area with leaf length and (q) leaf width, (r) leaf area with culm 1159 height, (s) culm height with leaf length and (t) leaf width and (u) leaf width with leaf length. 1160 Leaf trait and climate data provided in Supplementary Table 2. $N=1752$ globally distributed 1161 grass species in panels (a) - (i), (p), (q) and (u) and 1729 in panels (j) - (l), (r), (s) and (t).

1162 Corresponding regression coefficients for ahistorical analyses of relationships in panels (a) - (l): $11630.14,0.17,0.14,0.26,0.34,0.28,0.24,0.31,0.26,0.24,0.29$, and 0.3. Two-tailed 1164 phylogenetically reduced major axis (PRMA) regressions were fitted for $\log ($ trait $)=\log (a)+b$

$1165 \log$ (trait) in panels (a) - (l) and (p) - (u). Significance: $* * * P<0.001, * * P<0.01 . P=$ (a) 11660.0099 , (b) $7.8 \times 10^{-9}$, (c) $4.2 \times 10^{-9}$, (d) 0.004 , (e) $1.8 \times 10^{-8}$, (f) $2.4 \times 10^{-11}$, (g) 0.0014 , (h) $2.9 \times$ $116710^{-11}$, (i) $2.2 \times 10^{-13}$, (j) $1.7 \times 10^{-6}$, (k) $4.0 \times 10^{-7}$, (l) $1.1 \times 10^{-5}$, (p) $\sim 0$, (q) $\sim 0$, (r) $3.17 \times 10^{-219}$, 1168 (s) $1.92 \times 10^{-205}$, (t) $7.92 \times 10^{-106}$ and (u) $2.7 \times 10^{-96} \cdot \mathrm{C}_{3}$ and $\mathrm{C}_{4}$ species in red and blue, 1169 respectively.

1171 Extended Data Fig. 3. Worldwide association of grass leaf size with species' native climate 1172 in 3D, and binned by $\mathbf{1} / \mathbf{3}^{\text {rd }}$ lowest, middle and highest mean annual temperature (MAT, $1173{ }^{\circ} \mathbf{C}$ ), or mean annual precipitation (MAP, mm) in 2D. (a) Leaf area $\left(\mathrm{cm}^{2}\right)$ versus climate 1174 variables, i.e. $\mathrm{x}=$ mean annual temperature $\left(\mathrm{MAT},{ }^{\circ} \mathrm{C}\right)$ and $\mathrm{y}=$ mean annual precipitation (MAP, $1175 \mathrm{~mm}$ ) in panel (a) and (c), and the horizontal axes are flipped, i.e., leaf area versus $\mathrm{x}=$ MAP and $1176 \mathrm{y}=$ MAT in panels (b) and (d). Relationships of (e) - (g) Leaf length, (h) - (j) leaf width, (k) 1177 (m) leaf area, and (n) - (p) culm height with mean annual precipitation (mm); $n=584$ globally 1178 distributed grass species in panels (e) - (m) and 576 for panels (n) - (p). Relationships of (q) 1179 (s) Leaf length, (t) - (v) leaf width, (w) - (y) leaf area, and (z) - (bb) culm height with mean 1180 annual temperature $\left({ }^{\circ} \mathrm{C}\right) . N=584$ globally distributed grass species in panels (e) $-(\mathbf{m})$ and (q) 1181 (y) and 576 for panels (n) - (p) and (z) - (bb). Panels (a) and (b) present the data for all species 1182 in the global database $(N=1752)$; panels (c) and (d) exclude the 29 species with MAT $<0{ }^{\circ} \mathrm{C}$, 1183 for a clearer view of the bulk of the species. Projected grey shadows in (a) - (d) represent the 1184 bivariate relationships. Parameters from multiple regression analysis are presented in 1185 Supplementary Table 8. Two-tailed ordinary least square (OLS) regressions were fitted for $\log$ $1186 \quad($ trait $)=\log (a)+b \log ($ climate variable) in panels (e) - (bb). Significance: $* * * P<0.001, * * \mathrm{P}<$ $11870.01 . P=$ (e) $8.1 \times 10^{-5}$, (f) $2.2 \times 10^{-5}$, (g) 0.0002 , (h) 0.0094, (i) $8.4 \times 10^{-28}$, (j) $1.7 \times 10^{-21}$, (k) 
0.0002 , (l) $1.1 \times 10^{-20}$, (m) $1.8 \times 10^{-15}$, (n) 0.0028, (o) $4.7 \times 10^{-25}$, (p) $2.2 \times 10^{-10}$, (q) 0.0106 , (r) $2.9 \times 10^{-6}$, (t) $7.0 \times 10^{-5}$, (u) $6.7 \times 10^{-6}$, (v) $1.5 \times 10^{-17}$, (w) 0.0001 , (x) $7.9 \times 10^{-8}$, (y) $2.6 \times 10^{-11}$, (z) $1.3 \times 10^{-5}$, (aa) $1.7 \times 10^{-9}$ and (bb) $8.5 \times 10^{-10}$. $\mathrm{C}_{3}$ and $\mathrm{C}_{4}$ species in red and blue,

1191 respectively.

Extended Data Fig. 4. Quantile regression analyses of worldwide associations of grass leaf traits with species' native climate. Relationships of (a) - (c) Leaf length, (d) - (f) leaf width, (g) - (i) leaf area, and (j) - (l) culm height with mean annual temperature (MAT, ${ }^{\circ} \mathrm{C}$ ), mean annual precipitation (MAP, $\mathrm{mm}$ ) and aridity index (AI). $N=1752$ globally distributed grass species in panels (a) - (i) and 1729 in panels (j) - (l). Two-tailed ordinary least square (OLS; solid lines) and 95\% and 5\% quantile regressions (dotted lines) were fitted for $\log$ (trait) $=\log$ $(a)+b \log$ (climate variable); quantile lines drawn if significantly different in slope at $P<0.05$. $\mathrm{C}_{3}$ and $\mathrm{C}_{4}$ species in red and blue respectively.

Extended Data Fig. 5. Worldwide associations of grass leaf and plant dimensions with species' native climate, for species with leaf width $<8.16 \mathrm{~cm}$ or $<4.47 \mathrm{~cm}$, i.e. below the modelled threshold for damage due to night time chilling or overheating, and modeled leaf temperature difference from air temperature for amiphistomatous grass leaves under different air temperatures. Relationships of (a) - (b) Leaf length, (c) - (d) leaf width, (e) - (f) leaf area, and (g) - (h) culm height with mean annual temperature $\left(\mathrm{MAT},{ }^{\circ} \mathrm{C}\right)$ and mean annual precipitation (MAP, $\mathrm{mm}$ ) for species with leaf width $<8.16 \mathrm{~cm}$. Relationships of (i) - (j) Leaf length, (k) - (l) leaf width, (m) - (n) leaf area, and (o) - (p) culm height with mean annual

1210 temperature (MAT, ${ }^{\circ} \mathrm{C}$ ) and mean annual precipitation (MAP, mm) for species with leaf width $<$ $12114.47 \mathrm{~cm} . N=1748$ globally distributed grass species for panels (a) - (f), 1725 for panels (g) 1212 (h), 1716 for panels (i) - (n) and 1694 for panels (o) - (p). Simulations were run with stomatal 1213 conductance $\left(\mathrm{mol} \mathrm{m}^{-2} \mathrm{~s}^{-1}\right) \mathbf{( q )}-\mathbf{( t )} 0.1,(\mathbf{u})-(\mathbf{x}) 0.2$ and $(\mathbf{y})-(\mathbf{b b}) 0.4$, and wind speed $(\mathrm{m} / \mathrm{s})$, at 1214 (q), (u) and (y) 0.1, (r), (v) and (z) 0.5, (s), (w) and (aa) 1, (t), (x) and (bb) 2, with leaf width $1215(\mathrm{~cm})$ of $0.04,0.1,0.5,0.9,1.5,2.7$ and 11 shown as increasing darker blue lines. No difference in 1216 leaf temperature from air temperature line in red. Two-tailed ordinary least square (OLS) 1217 regressions were fitted for $\log ($ trait $)=\log (a)+b \log$ (climate variable) in panels (a) - (p).

1218 Significance: $* * * P<0.001, * * \mathrm{P}<0.01, * \mathrm{P}<0.05 . P=$ (a) $2.1 \times 10^{-8}$, (b) $6.2 \times 10^{-13}$, (c) $4.7 \times$ 
(d) $6.2 \times 10^{-48}$

(e) $2.0 \times 10^{-24}$, (f) $6.8 \times 10^{-40}$,

(g) $1.9 \times 10^{-24}$,

(h) $1.3 \times 10^{-33}$,

(i) $2.4 \times 10^{-7}$,

(j) $7.4 \times 10^{-11}$, (k) $1.0 \times 10^{-26}$, (l) $3.4 \times 10^{-39}$, (m) $5.4 \times 10^{-22}$,

(n) $9.8 \times 10^{-33}$,

(o) $4.4 \times 10^{-22}$ and

(p) $3.8 \times 10^{-29}$. $\mathrm{C}_{3}$ and $\mathrm{C}_{4}$ species in red and blue respectively.

\section{Extended Data Fig. 6. Worldwide scaling of grass vein length per leaf area and vein} diameter with leaf size and species' native climatic aridity, and of vein xylem conduit diameter with vein diameter. Relationships of major vein length per area with (a) and (c) leaf width, (b) and (d) leaf area and (c) aridity index (AI) (where lower values correspond to greater climatic aridity). Relationships of vein diameters with $(\mathbf{f}, \mathbf{i}, \mathbf{l}, \mathbf{o})$ leaf length, $(\mathbf{g}, \mathbf{j}, \mathbf{m}, \mathbf{p})$ leaf width and (h, k, n, q) leaf area ( = leaf length $\times$ leaf width). Relationships of vein length per area with (r, $\mathbf{u}, \mathbf{x}, \mathbf{a a})$ leaf length, $(\mathbf{s}, \mathbf{v}, \mathbf{y}, \mathbf{b b})$ leaf width and $(\mathbf{t}, \mathbf{w}, \mathbf{z}, \mathbf{c c})$ leaf area (leaf length $\times$ leaf width). Relationships of vein xylem conduit diameters with vein diameter (dd) first order $\left(1^{\circ}\right)$ veins, (ee) second order $\left(2^{\circ}\right)$ veins, (ff) third order $\left(3^{\circ}\right)$ veins and $(\mathbf{g g})$ fourth order $\left(4^{\circ}\right) . N=616$

1232 species in panels (a), 600 in panel (b), 170 in panel (c), 166 in panel (d), 21 in panel (e), 27 in 1233 panels (f) - (ff) and 7 in panel (gg). Two-tailed ordinary least square (OLS) regressions,

1234 phylogenetic generalized least square (PGLS) or phylogenetic reduced major axis (PRMA)

1235 regressions were fitted for $\log ($ trait $)=\log (a)+b \log$ (trait or climate variable) in panels (a) and 1236 (b), (c) and (d), and (e), respectively. Phylogenetic reduced major axis (PRMA) or phylogenetic generalized least square (PGLS) regressions were fitted for log (vein diameter or vein length per 1238 area $)=\log (a)+b \log$ (leaf length, width, or leaf area) in panels (f) $-(\mathbf{q})$, and (r) - (cc), respectively. Phylogenetic reduced major axis (PRMA) regressions were fitted for log (xylem conduit diameter $)=\log (a)+b \log ($ vein diameter $)$ in panels (dd) - (gg). $P^{*}<0.05, P^{* *}<0.01$, $P^{* * *}<0.001 . P=$ (a) $9.4 \times 10^{-250}$, (b) $1.6 \times 10^{-139}$, (c) (c) $7.0 \times 10^{-46}$ (d) $1.0 \times 10^{-31}$, (e) 0.0051 , (f) 0.0007 , (h) $3.0 \times 10^{-5}$, (i) $3.9 \times 10^{-6}$, (k) (k) 0.0003, (s) $1.2 \times 10^{-34}$ , (t) $7.0 \times 10^{-04}$, (v) $1.4 \times 10^{-7}$, (w) 0.0167, (bb) 0.0020, (dd) 0.0110 and (ee) 0.0004. Line parameters for panels (f) - (cc) in Table

12441 and Supplementary Table 10 and for (dd) - (gg) in Supplementary Table 11. Significant

1245 relationships are plotted with PRMA to illustrate the central trends (see Methods). $\mathrm{C}_{3}$ and $\mathrm{C}_{4}$

1246 species in white and grey respectively. Standard errors for species trait values are found in 1247 Supplementary Table 3. 
1250 Extended Data Fig. 7. Scaling of leaf vein projected area, vein surface area and vein volume 1251 of given vein orders with leaf dimensions across $27 C_{3}$ and $C_{4}$ grass species grown 1252 experimentally. Relationships of vein projected area with (a, d, g, j) leaf length, (b, e, h, k) leaf 1253 width and (c, f, i, l) leaf area (leaf width $\times$ leaf length). Relationships of vein surface area with 1254 (m, p, s, v) leaf length, (n, $\mathbf{q}, \mathbf{t}, \mathbf{w})$ leaf width, and $(\mathbf{o}, \mathbf{r}, \mathbf{u}, \mathbf{x})$ leaf area (leaf length $\times$ leaf width). 1255 Relationships of vein volume with (y, bb, ee, hh) leaf length, (z, cc, ff, ii) leaf width, and (aa, dd, $1256 \mathrm{gg}$, jj) leaf area (leaf width $\times$ leaf length). Two-tailed phylogenetic generalized least square 1257 (PGLS) regressions were fitted for log (vein projected area, vein surface area per area or vein 1258 volume $)=\log (a)+b \log$ (leaf length, width, or area) and drawn when significant. $P^{*}<0.05$, $1259 P^{* *}<0.01, P^{* * *}<0.001$; line parameters in Supplementary Table 10. $P=$ (a) 0.0011 , (b) $1.2 \times$ $126010^{-12}$, (d) 0.0011 , (e) $7.0 \times 10^{-5}$, (g) 0.0335 , (h) 0.0161 , (k) 0.0167 , (m) 0.0011 , (n) $1.2 \times 10^{-12}$, 1261 (p) 0.0011 , (q) $7.0 \times 10^{-5}$, (s) 0.0335 , (t) 0.0161 , (w) 0.0167 , (y) $8.2 \times 10^{-6}$, (z) $5.4 \times 10^{-6}$, (bb) $12625.2 \times 10^{-5}$, (cc) 0.0037 and (ff) 0.0093 . Significant trends are plotted with PRMA to illustrate the 1263 central trends (see methods). Standard errors for species trait values are found in Supplementary 1264 Table $3 . \mathrm{C}_{3}$ and $\mathrm{C}_{4}$ species in white and grey respectively.

Extended Data Fig. 8. Partitioning of the contributions of given vein orders of the venation architecture of $\mathrm{C}_{3}$ and $\mathrm{C}_{4}$ grasses, with minor veins accounting for the differences in vein length per area. (a) Triticum aestivum, a $\mathrm{C}_{3}$ species. (b) Aristida ternipes, a $\mathrm{C}_{4}$ species without $4^{\circ}$ veins $\left(\mathrm{C}_{4-3 \mathrm{~L}}\right.$; i.e., third-order veins are the highest longitudinal vein order). (c) Paspalum dilatum, a $\mathrm{C}_{4}$ species with $4^{\circ}$ veins $\left(\mathrm{C}_{4-4 L}\right.$; i.e., fourth-order veins are the highest longitudinal vein order). (d) Vein length per area $\left(\mathrm{cm} \mathrm{cm}^{-2}\right)$ distribution across vein orders for each type $\left(\mathrm{C}_{3} n=\right.$ $\left.11, \mathrm{C}_{4}-3 \mathrm{~L}=9, \mathrm{C}_{4}-4 \mathrm{~L}=7\right)$.

(e) Vein length per unit area, (f) vein surface area per unit leaf area, 1274 (g) vein projected area per unit leaf area and (h) vein volume per unit leaf area distribution across vein orders for each type $\left(C_{3} n=11, C_{4}=16\right)$. Statistical comparisons by phylogenetic

Extended Data Fig. 9. Associations of light-saturated leaf photosynthetic rate with native 1278 climate and vein traits for terrestrial $C_{3}$ species, and the scaling of transverse $5^{\circ}$ vein length 1279 per area ( $\left.5^{\circ} \mathbf{V L A}\right)$ with major vein length per area (major VLA) across $27 \mathrm{C}_{3}$ and $\mathrm{C}_{\mathbf{4}}$ grass 1280 species grown experimentally. Relationships of area-based light-saturated photosynthetic rate 
$1281\left(\mathrm{~A}_{\text {area }}\right)$, measured with photosynthesis systems, with (a) mean annual temperature (MAT, $\left.{ }^{\circ} \mathrm{C}\right),(\mathrm{b})$

1282 mean annual precipitation (MAP, mm), and (c) and growing season length (GSL, month).

1283 Relationships of light-saturated photosynthetic rate per area with (d) major vein length per area

1284 (VLA $\mathrm{VLjor}_{\text {m }}, \mathrm{cm} \mathrm{cm}^{-2}$ ) and (e) major vein surface area per area (VSA major, unitless), and (f)

1285 (transverse vein length per area $\left(\mathrm{VLA}_{\text {transverse }}, \mathrm{cm} \mathrm{cm}^{-2}\right)$ with $\mathrm{VLA}_{\text {major }}$. Points and lines in red

1286 represent 8 terrestrial $\mathrm{C}_{3}$ grasses of this study grown in a greenhouse common garden, related to

1287 the mean climate of their native distribution, supporting the assumption of higher photosynthetic

1288 rate in colder and drier climates with shorter growing seasons. Open points represent 13

1289 Northern Hemisphere temperate terrestrial $\mathrm{C}_{3}$ grass species from the global plant trait network

1290 (GLOPNET; ref 126) measured in the field, as related to the mean climate at their field site.

1291 Black lines represent the significant trend through all the points in panels (a) and (c), which,

1292 given the disparate data sources combined here (and the consideration of field site rather than

1293 native range climate for the GLOPNET species), provides yet stronger support for the generality

1294 of the relationships of $\mathrm{A}_{\text {area }}$ to MAT and GSL. Notably, these are conservative tests of the

1295 relationships of photosynthetic rate with native climate, as measurements of $\mathrm{A}_{\text {area }}$ using the

1296 photosynthesis system chamber do not include the effect of the boundary layer conductance,

1297 which is made very high and invariant ${ }^{23}$. Under natural conditions, and especially under slow

1298 windspeeds, smaller leaves would have higher boundary layer conductances than larger leaves

1299 (see simulation in Extended Data Fig. 5), and thus, under natural conditions, including the effects

1300 of boundary layer, a yet stronger trend would be expected for small-leaved species of colder and

1301 drier climates to have higher photosynthetic rates than larger-leaved species of warm, moist

1302 climates. Two-tailed ordinary least square (OLS) regressions or phylogenetic reduced major axis

1303 (PRMA) were fitted for $\log ($ trait $)=\log (\mathrm{a})+\mathrm{b} \log ($ trait or climate variable) in panels (a) - (e)

1304 and (f), respectively. Significance: $P^{*}<0.05, P^{* *}<0.01, P^{\mathrm{x}}=0.04$ in a one-tailed test of the

1305 hypothesized positive correlation. $P=$ (a) 0.0301 red line; 0.0071 black line, (b) 0.0183, (c)

$1306 \quad 0.0474$ red line; 0.0021 black line, (d) 0.0794, (e) 0.0138 and (f) 0.0061. Error bars represent

1307 standard errors in panels (a) - (e). Standard errors for species trait values in panel (f) are found in

1308 Supplementary Table $3 . \mathrm{C}_{3}$ and $\mathrm{C}_{4}$ species in white and grey, respectively, in panel (e).

1309

1310 Extended Data Fig. 10. Estimating leaf size from venation traits that can be measured on

1311 small samples or fragments of grass leaves. (a) Leaf area and (b) leaf width predicted from $2^{\circ}$ 
1312 vein length per area. $N=600$ and 616 in panels (a) and (b) respectively (Grassbase dataset; 1313 Supplementary Table 2). The relationships were fitted with two-tailed ordinary least square 1314 (OLS) regressions. These relationships would enable the determination of intact leaf size from 1315 fragments that include at least two $2^{\circ}$ veins, including fragmentary fossil remains. The $95 \%$ 1316 confidence intervals are in blue and $95 \%$ prediction intervals in red. $P^{* * *}<0.001 . P=($ a) $1.4 \times$ $1317 \quad 10^{-127}$ and (b) $7.6 \times 10^{-227}$. 


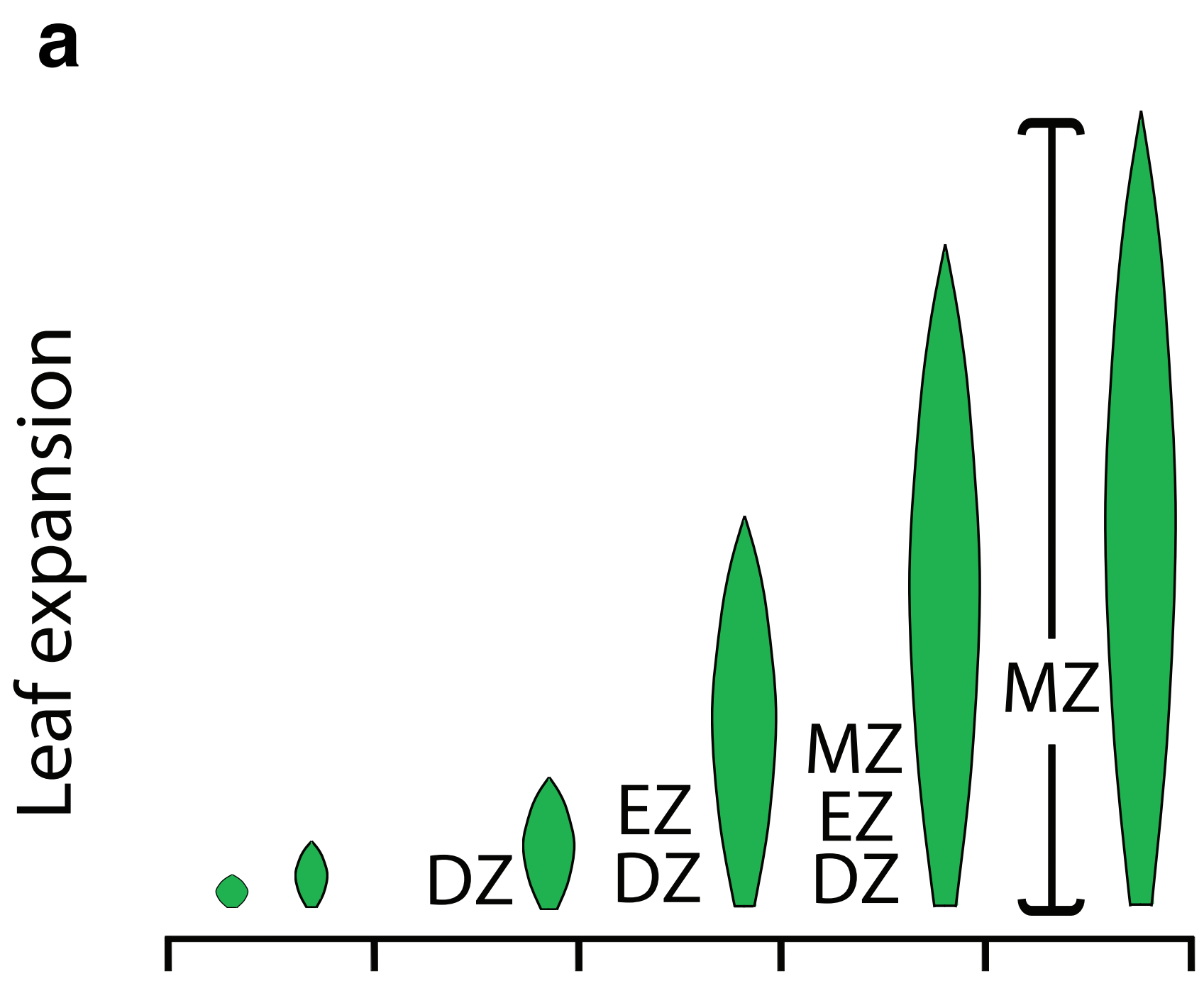




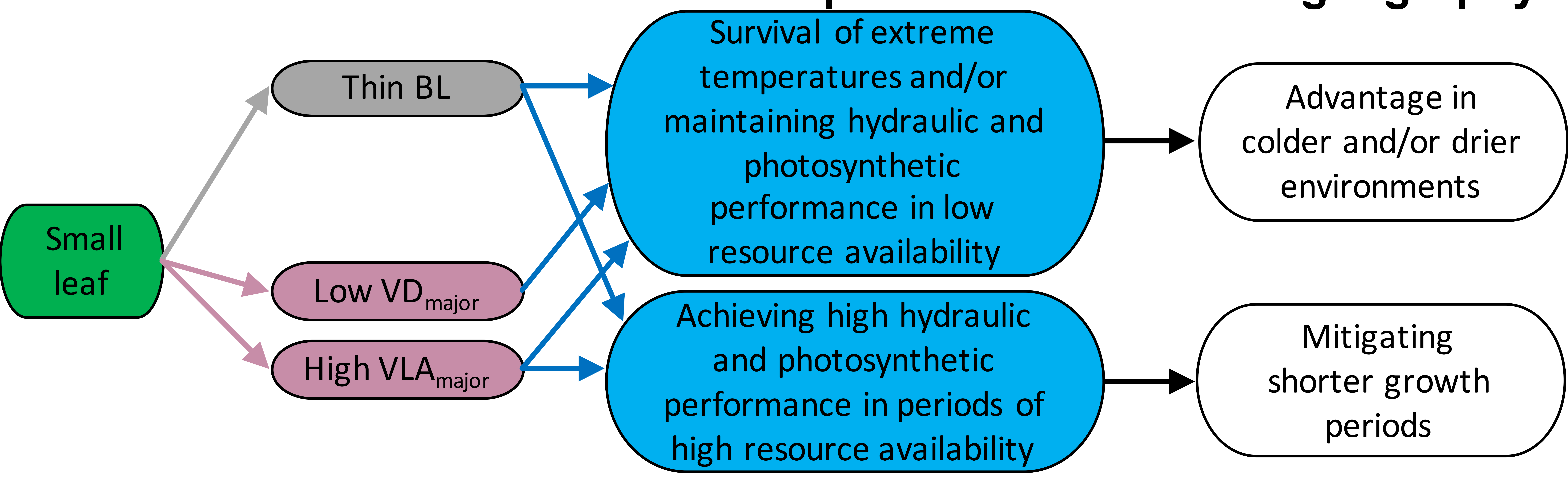

b

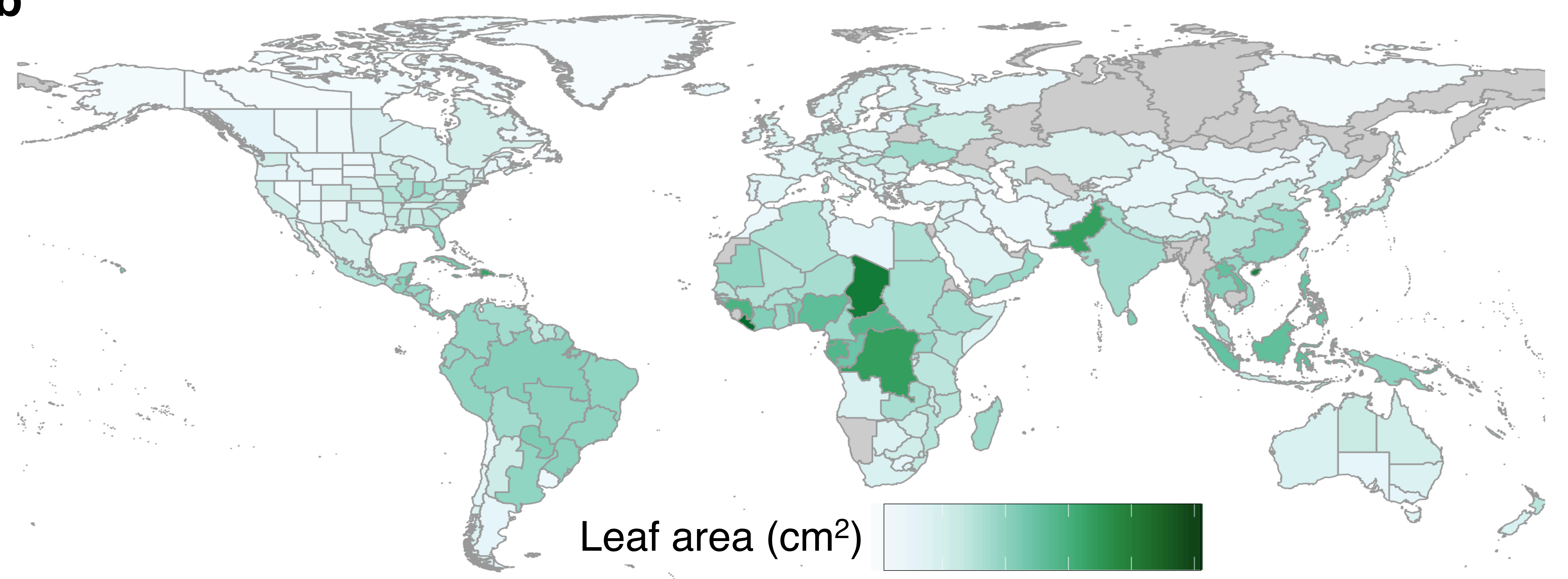

C

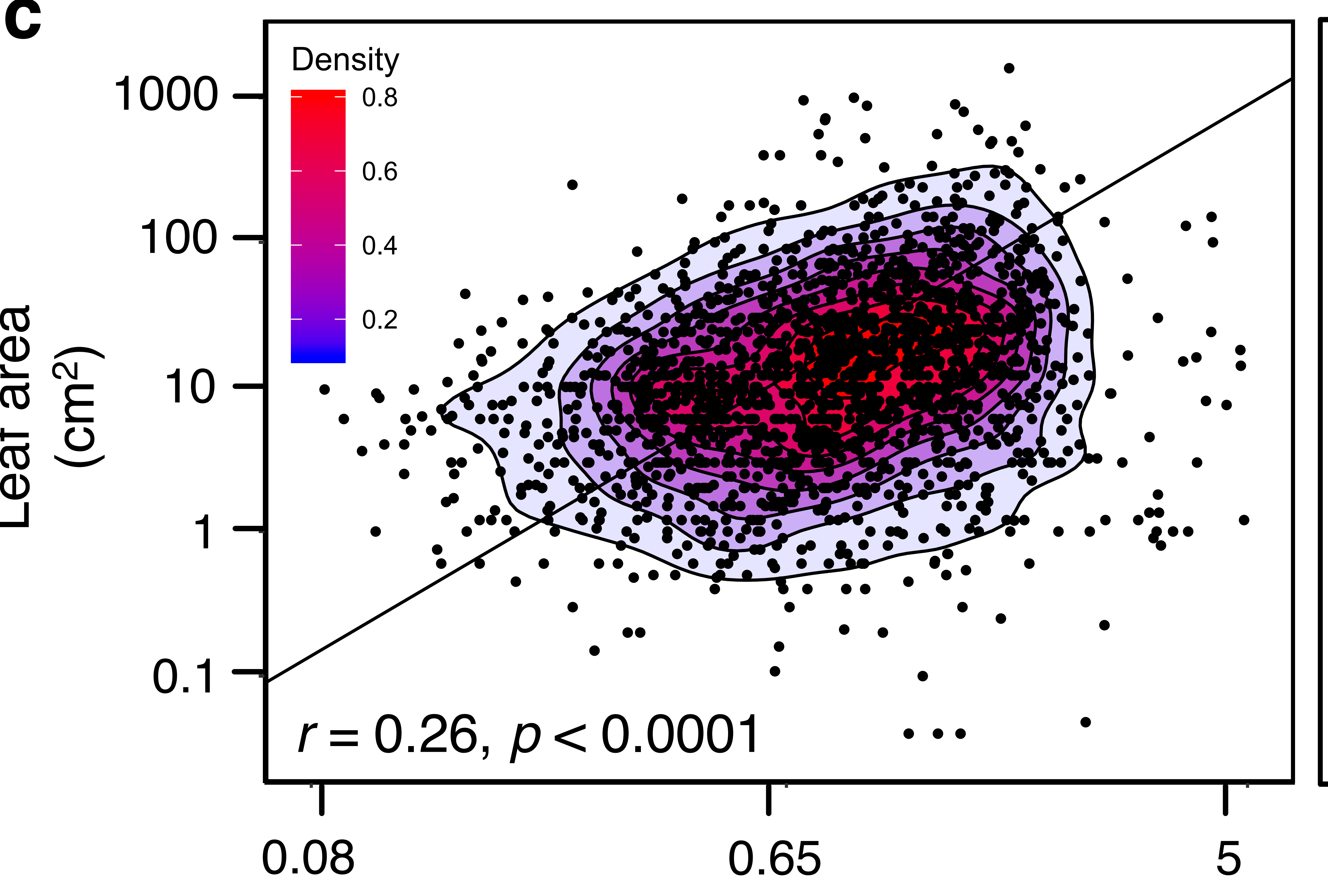

Aridity index

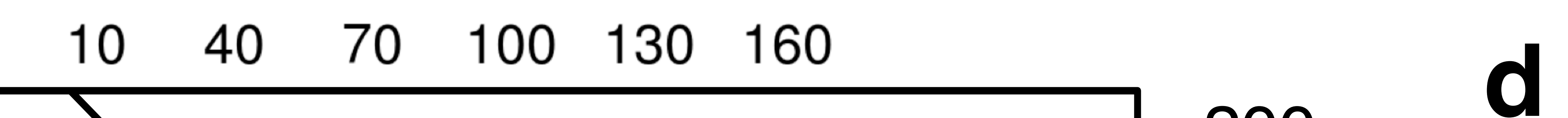

$b=-0.47$

$r=-0.81, p<0.0001$

0.1

10

Leaf area $\left(\mathrm{cm}^{2}\right)$ 







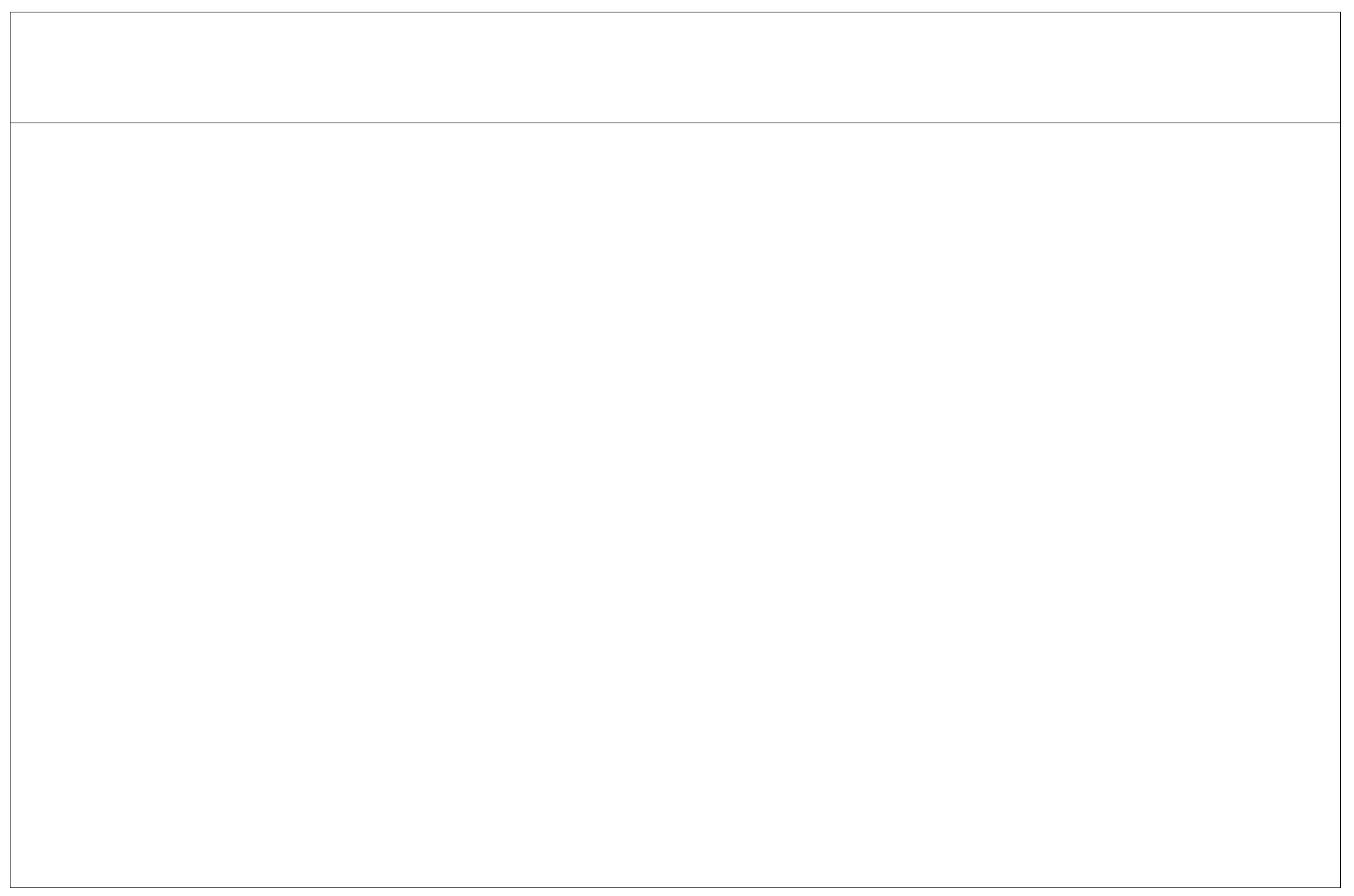

